Article

\title{
Marine-Derived Quorum-Sensing Inhibitory Activities Enhance the Antibacterial Efficacy of Tobramycin against Pseudomonas aeruginosa
}

\author{
Alessandro Busetti ${ }^{1}$, George Shaw ${ }^{1}$, Julianne Megaw ${ }^{1}$, Sean P. Gorman ${ }^{1}$, \\ Christine A. Maggs ${ }^{2}$ and Brendan F. Gilmore ${ }^{1, *}$
}

1 School of Pharmacy, Queen's University Belfast, 97 Lisburn Rd, Belfast BT9 7BL, UK; E-Mails: a.busetti@qub.ac.uk (A.B.); gshaw08@qub.ac.uk (G.S.); j.megaw@qub.ac.uk (J.M.); s.gorman@qub.ac.uk (S.P.G.)

2 School of Biological Sciences, Medical Biology Center, 97 Lisburn Road, Belfast BT9 7BL, UK; E-Mail: c.maggs@qub.ac.uk

* Author to whom correspondence should be addressed; E-Mail: b.gilmore@qub.ac.uk; Tel.: +44-0-28-9097-2305; Fax: +44-0-28-9024-7794.

Academic Editor: Miguel Mitchell

Received: 27 October 2014 / Accepted: 15 December 2014 / Published: 24 December 2014

\begin{abstract}
Bacterial epiphytes isolated from marine eukaryotes were screened for the production of quorum sensing inhibitory compounds (QSIs). Marine isolate KS8, identified as a Pseudoalteromonas sp., was found to display strong quorum sensing inhibitory (QSI) activity against acyl homoserine lactone (AHL)-based reporter strains Chromobacterium violaceum ATCC 12472 and CV026. KS8 supernatant significantly reduced biofilm biomass during biofilm formation $(-63 \%)$ and in pre-established, mature $P$. aeruginosa PAO1 biofilms (-33\%). KS8 supernatant also caused a $0.97-\log$ reduction $(-89 \%)$ and a 2-log reduction $(-99 \%)$ in PAO1 biofilm viable counts in the biofilm formation assay and the biofilm eradication assay respectively. The crude organic extract of KS8 had a minimum inhibitory concentration (MIC) of $2 \mathrm{mg} / \mathrm{mL}$ against PAO1 but no minimum bactericidal concentration $(\mathrm{MBC})$ was observed over the concentration range tested $(\mathrm{MBC}>16 \mathrm{mg} / \mathrm{mL})$. Sub-MIC concentrations $(1 \mathrm{mg} / \mathrm{mL})$ of KS8 crude organic extract significantly reduced the quorum sensing (QS)-dependent production of both pyoverdin and pyocyanin in $P$. aeruginosa PAO1 without affecting growth. A combinatorial approach using tobramycin and the crude organic extract at $1 \mathrm{mg} / \mathrm{mL}$ against planktonic $P$. aeruginosa PAO1 was found to increase the efficacy of tobramycin ten-fold, decreasing
\end{abstract}


the MIC from 0.75 to $0.075 \mu \mathrm{g} / \mathrm{mL}$. These data support the validity of approaches combining conventional antibiotic therapy with non-antibiotic compounds to improve the efficacy of current treatments.

Keywords: antibiotic resistance; antimicrobial synergy; quorum sensing inhibitors; marine bacteria; biofilm; marine biodiscovery; tobramycin; Pseudomonas aeruginosa

\section{Introduction}

The emergence, spread and evolution of antimicrobial resistance (AMR) amongst microorganisms is an ancient biological phenomenon and a direct consequence of the selective pressure imposed by natural selection [1]. The mechanisms that lead to the emergence and diffusion of AMR are multiple and include mutation (stochastic or mutagen-induced), gradual increased tolerance to sub-lethal concentrations of compounds, horizontal gene transfer through mobile genetic elements (plasmids, transposons and insertion sequences) and recombination events (such as those between a bacteriophage and a bacterial host) [2,3].

The discovery of antibiotics [4] and their use as therapeutics has resulted in drastic decreases in morbidity and mortality associated with bacterial infectious diseases (the "antibiotic era"). Paradoxically, anthropogenic use of antibiotics both in the clinical setting and in non-therapeutic theatres of human activity such as agriculture and zootechny [5] has accentuated natural selective pressure on bacterial pathogens, accelerating the acquisition and diffusion of resistance, undermining the efficacy of antibiotics in the clinical context. For example, MRSA infections in the US are currently responsible for more deaths than HIV/AIDS and tuberculosis combined [6,7]. The selective pressures induced by antimicrobial use are particularly evident in the nosocomial environment where clear relationships between antimicrobial use and the emergence of multiresistant, extensively drug-resistant and pan-drug-resistant strains have been observed [8,9]. Despite concerted efforts, the discovery of new antibiotics has considerably slowed down and the number of new antibacterial drugs gaining FDA approval in the United States continues to fall [10]. Without such tools we can expect to witness a substantial rise in incurable chronic infection and fatality in both underdeveloped and developed regions of the globe. This imminent global health threat has spurred research investigating novel therapeutic strategies based on new targets and approaches aimed at circumventing the emergence of antimicrobial resistance.

The discovery and elucidation of the mechanisms underlying bacterial density-dependent cell-to-cell signaling relying on small diffusible signaling molecules, known as quorum sensing (QS) [11], has offered promising novel targets for antivirulence approaches aimed at disarming rather than killing human pathogens during the course of colonization and infection. In fact, many Gram positive and Gram negative bacteria use QS to coordinate behaviors and regulate a diverse array of physiological activities including swarming [12], bioluminescence [13], symbiosis [14], virulence [15], competence [16], production of extracellular enzymes [17], conjugation [18], sporulation [19], antibiotic synthesis [20], biofilm formation [21,22] and to regulate the production of factors used to scavenge for nutrients, actuate immune suppression, provide scaffolding for biofilms to grow and aid motility [23]. 
The dramatically rapid and continuous emergence of antibiotic resistance in the clinical context necessitates the urgent identification of novel strategies for treating bacterial infections, including non-antibiotic based approaches. QS inhibition represents an emerging, promising strategy to render pathogens more susceptible to antibiotics and hinder adaptation to host immune response, attenuating bacterial virulence by limiting the emergence of pathogenic traits [15,24]. In fact, it has been shown that by inhibiting QS, a disruption of the signaling systems controlling the production and release of a number of virulence factors is achieved. For example, the expression of AHL lactonase (enzymes which catalyze the opening of the lactone ring component of the AHL molecule [24]) in the human pathogens $P$. aeruginosa and Burkholderia species resulted in large decreases in virulence gene expression and swarming motility [25] and the attenuation of virulence [26,27]. In agricultural applications, the expression of AHL lactonase in transgenic tobacco leaves and potatoes significantly enhanced resistance against Erwinia carotovora infections, a pathogen reliant on AHL-mediated quorum-sensing for its virulence [28]. Halogenated furanones are another well-characterized class of marine-derived compounds shown to possess QSI activity against a broad range of bacteria [29,30]. These compounds antagonize AHL-dependent gene expression through accelerated degradation of the LuxR-type transcriptional activator [31], inhibiting virulence factor expression [15]. Overall, QS inhibition can be considered an 'anti-virulence' approach based on the use of molecules capable of disarming pathogens within their host by targeting specific factors necessary for successful infection, such as toxin biosynthesis and function, toxin delivery, virulence gene regulation, or cell adhesion [32-34].

Although the role of QS in regulating antimicrobial susceptibility still needs to be fully elucidated, several studies using both in vitro and in vivo models have shown increased susceptibility of pathogenic bacteria to antibiotics when used in combination with QSIs [35-37]. These promising results suggest the possibility of using QSIs in combination with current and future antibiotics at lower therapeutic concentrations, reducing toxicity for the patient. Moreover, as QS is not involved in essential cellular processes, QSI strategies are less likely to generate resistance [24,38]. It has been hypothesized that the emergence of QSI resistance would be selected in vivo during infection whenever QS promotes colonization, systemic spread, or immune evasion [39]. However the use of a joint antimicrobial/antivirulence approach would considerably reduce the likelihood of the emergence of such a resistance.

Pseudomonas aeruginosa is a common Gram negative opportunistic pathogen associated with biofilm-related nosocomial infections [40,41] and to chronic lung infection in cystic fibrosis (CF) sufferers, where such infections constitute the major cause of patient morbidity and mortality [42,43]. It utilizes three different QS circuits to regulate the production of virulence factors and promote biofilm maturation [44,45]. The lasI/lasR and rhlI/rhlR QS circuits are based on AHL signaling molecules and regulate 170-400 genes via a complex network [30,46,47] making this pathogen an excellent candidate for the use of antivirulence approaches based on the use of QSIs.

The aqueous nature of the marine environment allows the constant development of a ubiquitous microbial biofilm covering the majority of submerged surfaces [48]. In this environment, natural selection has bestowed an evolutionary advantage to microorganisms with an array of chemical defenses enabling them to compete for space, nutrients and light during the colonization of biotic or abiotic surfaces. In particular, a large number of marine natural compounds isolated from a variety of marine organisms possess QSI activity [49] suggesting QS inhibition has evolved as a natural, 
widespread, antimicrobial strategy with significant impact on biofilm formation, making the marine ecosystems an ideal source for the discovery of QS inhibitors with the potential to increase susceptibility of human pathogens to antibiotics.

\section{Results and Discussion}

Initially, 26 marine bacterial isolates were screened for the production of QSIs against the Gram negative AHL-based reporter strains C. violaceum ATCC 12472, and CV026. Nine isolates (ISO1, ISO2, ISO6, KS6, KS8, GS5, JUN4, LL67 and A15-1) were found to strongly inhibit QS-dependent violacein production in both C. violaceum ATCC 12472 (Figure 1) and C. violaceum CV026 (data not shown). C. violaceum ATCC 12472 regulates pigment production in response to $N$-hexanoyl-L-homoserine lactone (C6-HSL) [50]. Although reporter strain C. violaceum ATCC 12472 is a useful tool to detect QSI activity, it provides no further information with regards to the mechanism of action of the compounds involved in the QSI activity displayed by isolates. The three key targets of a QSI drug approach against Gram negative pathogens that use an AHL-based QS system are the signal molecule generator (LuxI-type synthases), the signal molecule itself (AHL) and the signal molecule receptor (Lux-R-type transcription factors. For example, it is known that an inactivation of the LuxI-type synthase can block the production of the relative AHL signaling molecule [24]. QS can also be inhibited by targeting the signal molecule itself with the main proposed strategies being metabolic, chemical and enzymatic degradation or inactivation. The third target for QSI is the LuxR transcription factor. For example, small AHL analogues have been used to block the activation of LuxR inhibiting downstream activation of QS-regulated pathways [24,51]. C. violaceum (CV026) is a mini-Tn5 mutant where the transposon insertion sites have been mapped to a putative repressor locus and to a lux homologue (cviI) and in which violacein production can be restored by incubation with supernatants from the wild-type strain [52,53]. As the QSI assay using reporter strain CV026 requires exogenous addition of C6-AHL signaling molecule, the results suggest the QSI activity of KS8 observed against the wild type $C$. violaceum is not attributable to the inactivation of the components involved in the synthesis of the signal molecule. Based on the strength of the QSI activity and the lack of antimicrobial activity displayed by isolate KS8 against reporter strains C. violaceum ATCC 12472 and CV026, screening of this isolate for QSI was repeated using reporter strain Serratia sp. ATCC 39006. This reporter strain produces the red pigment prodigiosin in response to the short-chain signal $N$-butanoyl-L-homoserine lactone (C4-HSL) [54], the same AHL used in the Pseudomonas aeruginosa $\mathrm{rhlI} / \mathrm{rhlR}$ QS system which regulates the expression of $\operatorname{rhlAB}$ (rhamnolipid), lasB, aprA, RpoS, cyanide, pyocyanin [55-57] and the lectins PA-I and PA-II [58]. Isolate KS8 caused inhibition of pigment production in its proximity, indicative of putative QSI activity (Supplementary Figure S1). When interpreted in conjunction to the results on C. violaceum ATCC 12472 and CV026, the QSI activity observed against Serratia sp. ATCC 39006 suggests the inhibition of QS by KS8 is likely to be broad-spectrum rather than dependent on the structure of the AHL molecule itself. 


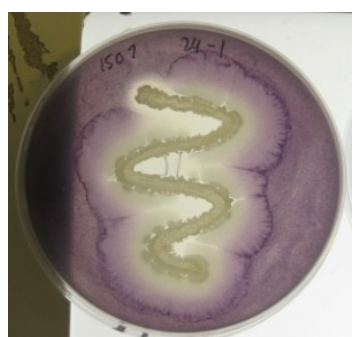

(A)

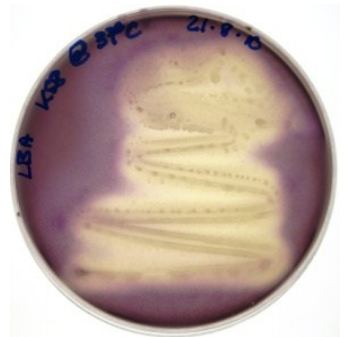

(E)

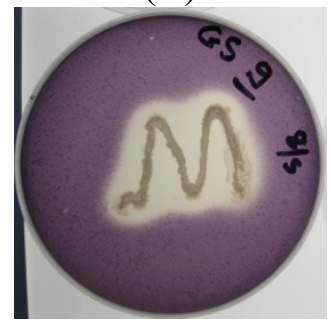

(I)

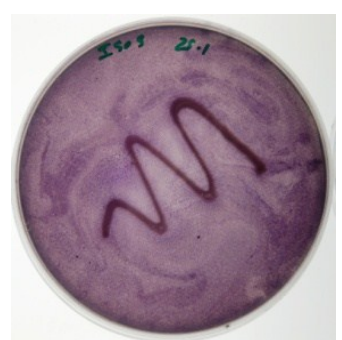

(B)

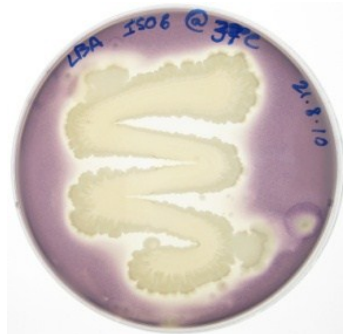

(F)

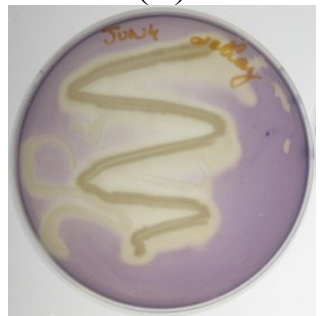

(J)

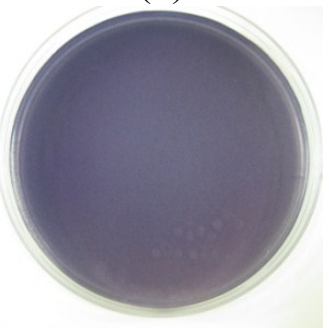

(M)

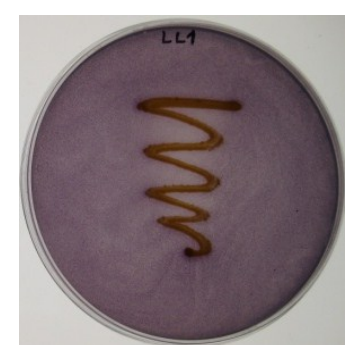

(C)

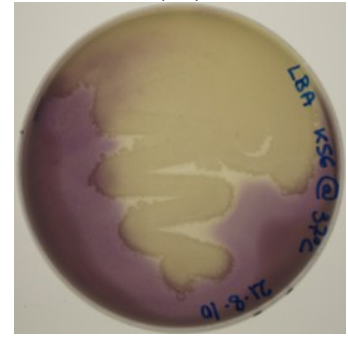

(G)

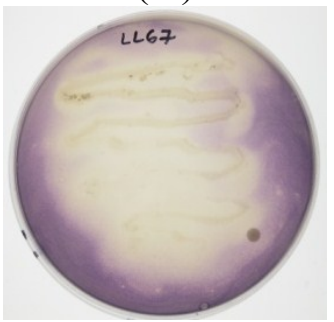

(K)

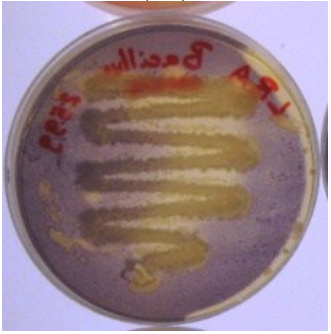

(N)

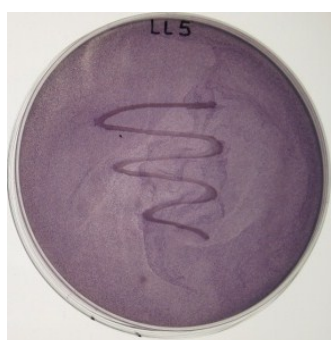

(D)

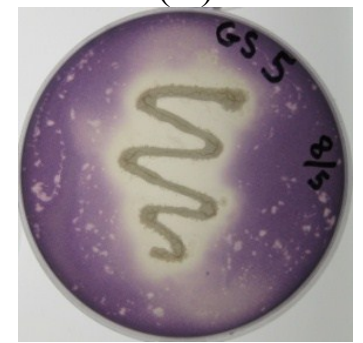

(H)

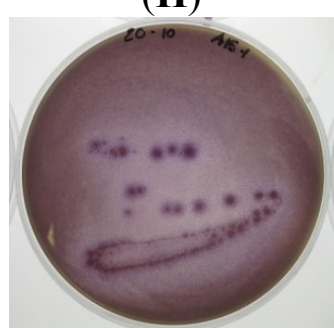

(L)

Figure 1. Quorum sensing inhibitory compound (QSI) screening of bacterial isolates using reporter strain C. violaceum ATCC 12472; (A) ISO1, weak antimicrobial activity, strong QSI activity; (B) ISO9 no QSI activity detected; (C) LL1 no QSI activity detected; (D) LL5 no QSI activity detected; (E) KS8 strong QSI activity; (F) ISO6 strong QSI activity; (G) KS6 strong QSI activity; (H) GS5 medium-strong QSI activity and weak antimicrobial activity; (I) GS9 no QSI activity and medium-strong antimicrobial activity; (J) JUN4 strong QSI activity; (K) LL67 strong QSI activity; (L) A15-1 weak QSI activity; (M) C. violaceum ATCC 12472, negative QSI control; (N) B. cereus NCTC 9945 harboring the aiiA lactonase gene (positive QSI control) displaying modest QSI activity.

To test whether the QSI activity displayed by the nine bacterial isolates was correlated to antibiofilm activity, the isolates' filter-sterilized supernatants were screened for the ability to inhibit biofilm formation (Figure 2) and eradicate pre-established biofilms (Figure 3) of P. aeruginosa PAO1. The supernatant of isolate KS8 caused a significant reduction in the mean absorbance of stained biomass of $P$. aeruginosa PAO1 biofilm (-63\%) (Figure 2) over 24 h (Figure 2 and Table 1), suggesting 
the presence of compounds capable of interfering with the maturation of the biofilm. For example, the presence of growth-inhibiting bioactives could be responsible for slowing down biofilm growth, whilst failing to have an effect on the long-term final total biomass produced by the test pathogen

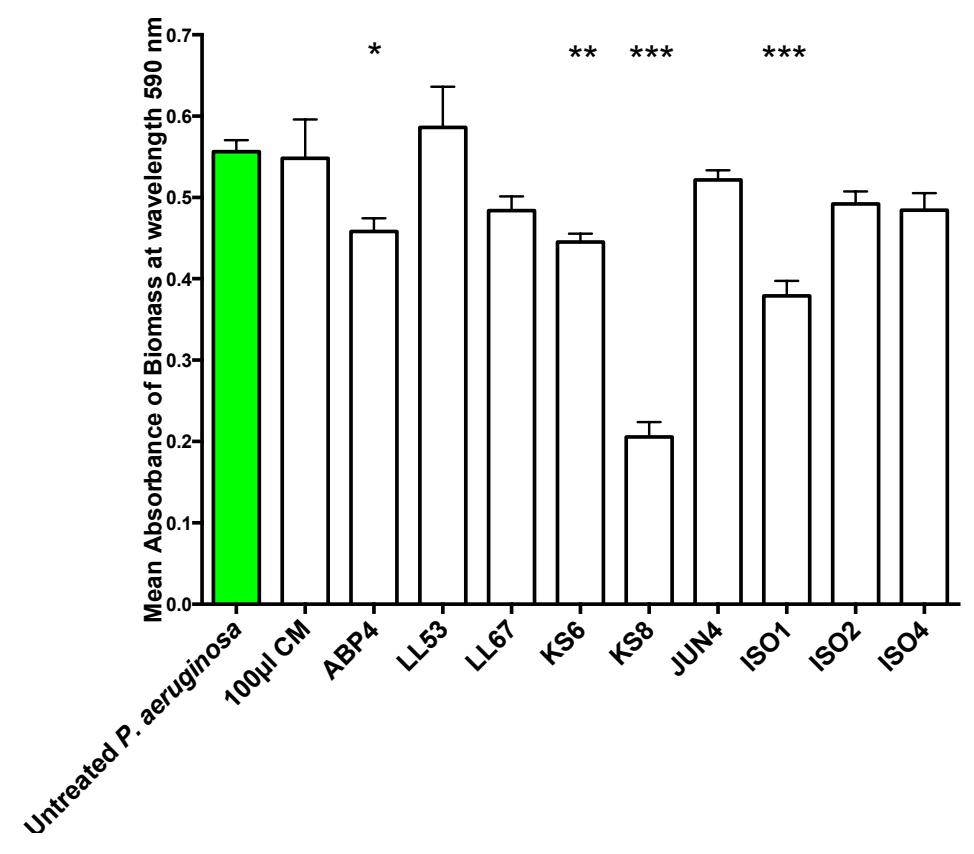

Figure 2. Biofilm prevention assay. $24 \mathrm{~h}$ biofilm biomass (mean absorbance of biomass at $590 \mathrm{~nm}$ ) of $P$. aeruginosa PAO1 (green) following $24 \mathrm{~h}$ exposure to $100 \mu \mathrm{L}$ of sterile 3-day supernatants of marine isolates ABP4, LL53, LL67, KS6, KS8, JUN4, ISO1, ISO2, ISO4. $\mathrm{CM}=$ Conditioned media. Differences in mean absorbance were compared to the untreated control at each time-point and considered significant when $p<0.05(* p<0.05$, $* * p<0.01, * * * p<0.001)$ according to the non-parametric Kruskal Wallis test with Dunn's Multiple Comparison Test.

KS8 supernatant also caused a significant reduction of $P$. aeruginosa PAO1 $(-33 \%)$ biomass in pre-established $24 \mathrm{~h}$ biofilms following $24 \mathrm{~h}$ treatment with KS8 supernatant (biofilm removal) (Figure 3, Table 1). The mean absorbance of biofilm biomass for $24 \mathrm{~h}$ PAO1 biofilms (0.67 O.D. at $590 \mathrm{~nm})$ did not vary significantly from the mean absorbance of untreated $48 \mathrm{~h}$ biofilms confirming biofilms had reached full maturity and remained relatively intact during the $24 \mathrm{~h}$ test period. The results of the biofilm eradication assay also suggest the inhibition of biofilm formation is unlikely to be attributable to growth inhibition, and although possibly multifactorial in nature, the reduction in biofilm biomass could involve the upregulation of dispersal mechanisms. In fact, compounds such as dispersin B and nitric oxide have been shown to affect biofilm formation by promoting cell dispersal [59].

All of the nine isolates tested failed to completely prevent biofilm formation or completely eradicate pre-established test biofilms. Several concurrent factors could have contributed to the modest antibiofilm activities observed. Firstly, as the isolates being tested produced putative QSIs, it is unlikely for QS inhibition to completely prevent adhesion or promote complete biofilm dispersion/ eradication. In fact, QSIs are rather more likely to affect the structure, physiology and maturation of the biofilm. Moreover, to avoid stressing the test biofilms due to starvation, supernatants were diluted 
in fresh Luria Bertani (LB) broth and as a result, the bioactives present could have been diluted below effective concentrations.

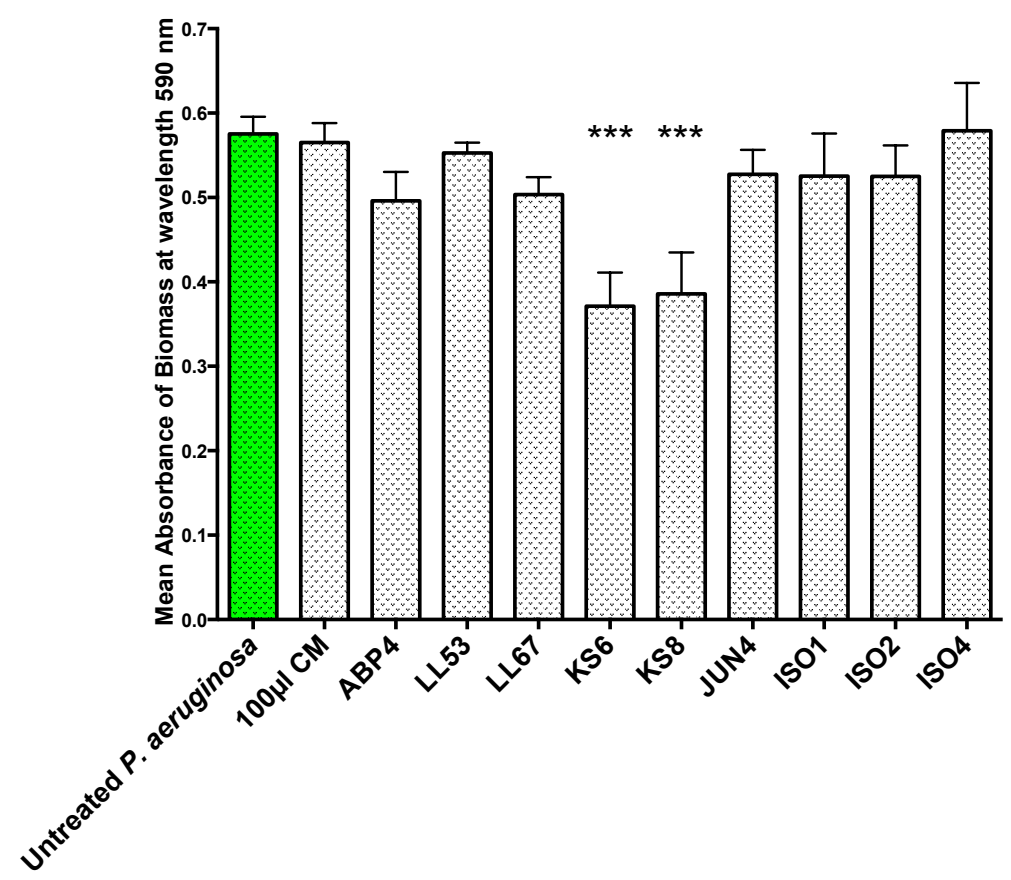

Figure 3. Biofilm removal assay. $48 \mathrm{~h}$ biofilm biomass (mean absorbance of biomass at $590 \mathrm{~nm}$ ) of $P$. aeruginosa (PAO1) biofilms following $24 \mathrm{~h}$ challenge using $100 \mu \mathrm{L}$ of sterile 3-day supernatants of marine isolates ABP4, LL53, LL67, KS6, KS8, JUN4, ISO1, ISO2, ISO4. $\mathrm{CM}=$ Conditioned media. Differences in mean absorbance were compared to the untreated control at each time-point and considered significant when $p<0.05$ $(* p<0.05, * * p<0.01, * * * p<0.001)$ according to the non-parametric Kruskal Wallis test with Dunn's Multiple Comparison Test.

Table 1. Summary of the percent reduction of $P$. aeruginosa (PAO1) biofilm biomass following $24 \mathrm{~h}$ challenge using sterile $72 \mathrm{~h}$ KS8 supernatant during biofilm formation and on mature, pre-established $24 \mathrm{~h}$ P. aeruginosa (PAO1) biofilms (biofilm removal assay). Differences in mean absorbance compared to the untreated control of each time-point were considered significant when $p<0.05(* p<0.05, * * p<0.01, * * * p<0.001)$ according to the non-parametric Kruskal Wallis test with Dunn's Multiple Comparison Test.

\begin{tabular}{cccc}
\hline Isolate & Closest Typed Species (NCBI) & Biofilm Formation & Biofilm Removal \\
\hline & & $P A O 1$ & $P A O 1$ \\
KS8 & Pseudoalteromonas $\mathrm{sp}$. & $-63 \%(* * *)$ & $-33 \%(* * *)$ \\
\hline
\end{tabular}

The antibiofilm activity displayed by the culture supernatant of isolate KS8 appeared to be more significant during biofilm formation than in the removal of pre-established $24 \mathrm{~h}$ biofilms. There are several factors that could have contributed to this result. The copious production of extracellular polymeric substances, a characteristic feature of established and mature $P$. aeruginosa biofilms, can limit the diffusion of bioactives and is often the site of enzymatic deactivation/degradation of 
antimicrobials providing protection against mechanical removal, predation, and exogenous antimicrobial insult whilst securing the presence of a suitable biofilm microenvironment $[60,61]$.

Based on the consistent antibiofilm activity displayed in the microtitre crystal violet assay by the supernatant of isolate $\mathrm{KS} 8$, both preventing biofilm formation and promoting the eradication of mature $24 \mathrm{~h}$ biofilms of $P$. aeruginosa PAO1, this isolate was selected for further studies. A $758 \mathrm{bp} 16 \mathrm{~S}$ rRNA gene sequence was obtained following DNA extraction and PCR and used to identify KS8 (isolated from the marine Bryozoan Scrupocellaria sp.) using the basic local alignment search tool (BLAST) of the NCBI database. Five accession numbers belonging to the genus Pseudoalteromonas were found to share a 99\% sequence identity with KS8, all with an E-value of zero and a max score of 1393 allowing identification to the genus level. Various members of the genus Pseudoalteromonas have been shown to produce antibiofilm compounds. For example, the exoproducts of Pseudoalteromonas sp. 3J6 isolated from marine biofilms grown on glass slides impaired biofilm formation of Paracoccus sp. 4M6, Vibrio sp. D01 and the three human-pathogenic species Pseudomonas aeruginosa, Salmonella enterica, and Escherichia coli, leading to a higher percentage of non-viable cells in $48 \mathrm{~h}$ biofilms and reduced bacterial attachment on coated glass slides [62]. Another member of this genus, Pseudoalteromonas tunicata D2, has been shown to secrete the autotoxic $190 \mathrm{kDa}$ dimeric antibacterial protein AlpP which gives a competitive advantage for the latter for biofilm formation in the marine environment and for the colonization of the surface of the green alga Ulva australis [62]. In fact, AlpP is able to inhibit a variety of marine and medically important bacteria [63] and has been shown to be particularly autotoxic with an MIC of $4 \mu \mathrm{g} / \mathrm{mL}$ [64]. It has been hypothesized that by working through an apoptosis-like mechanism, the autoxicity of AlpP provides a dispersal mechanism to biofilm dwelling P. tunicata [65], where the self-induced lysis of cells causes sections of the biofilm to rip and shed but also supplies nutrients to survivor cells resistant to AlpP [62]. The survivor cells contained in the "floccules" of shed biofilm actively disperse in the surrounding water in search of new surfaces to colonize [66,67]. The genus Pseudoalteromonas is also well known for the production of antibacterial, antifungal, antiviral and/or algicidal molecules. For example, a closely related species, Pseudoalteromonas atlantica, isolated from Cancer pagurus (edible crab) [68] was found to produce a variety of biologically active extracellular compounds such as extracellular polysaccharides responsible for influencing succession in marine communities, eventually leading to the settlement of higher organisms such as tunicates and oyster larvae [69].

As the crystal violet microtitre plate assay measures biomass but fails to take into account cell viability, the study of the prevention of biofilm formation and biofilm eradication following exposure to the bioactives produced by isolate KS8 was conducted using the Calgary Biofilm Device (CBD, MBEC $^{\text {TM }}$ assay for Physiology \& Genetics, Innovotech, Edmonton, Alberta, Canada). To determine an optimal incubation period for the production of bioactives, biofilm formation studies were conducted using 24, 72 and $240 \mathrm{~h}$ supernatants. Biofilm formation of P. aeruginosa PAO1 was significantly inhibited by the higher concentrations (100 and $200 \mu \mathrm{L}$ ) of all sterile KS8 supernatants (Figure 4) however the $72 \mathrm{~h}$ supernatant also caused a significant reduction when diluted in a 1:4 ratio $(50 \mu \mathrm{L})$, and was thus chosen as the incubation time for the studies to follow. Although significant, the mechanism of such inhibition remains to be elucidated and it is unclear whether the reduction in biofilm formation by $P$. aeruginosa PAO1 is attributable to a reduced capacity to metabolize media, an increased rate of dispersal, a growth inhibitory effect or to a combination of effects. The sterile 3-day 
supernatant of isolate KS8 also displayed a significant antibiofilm activity (biofilm eradication) against mature $P$. aeruginosa PAO1, causing a 99\% reduction in biofilm viable counts (Figure 5 and Table 2). The viable counts $\left(\log _{10} \mathrm{bfu} / \mathrm{peg}\right)$ of untreated $24 \mathrm{~h}$ PAO1 biofilms (7.264) did not vary significantly from the viable counts of untreated $48 \mathrm{~h}$ PAO1 biofilms (7.444) confirming the activities observed did not depend on the removal of biofilm or on the inhibition of growth during the test period (Supplementary Figure S2). Further work will be necessary to elucidate the mechanisms underlying the inhibition of biofilm formation and the biofilm eradication observed against this pathogen.

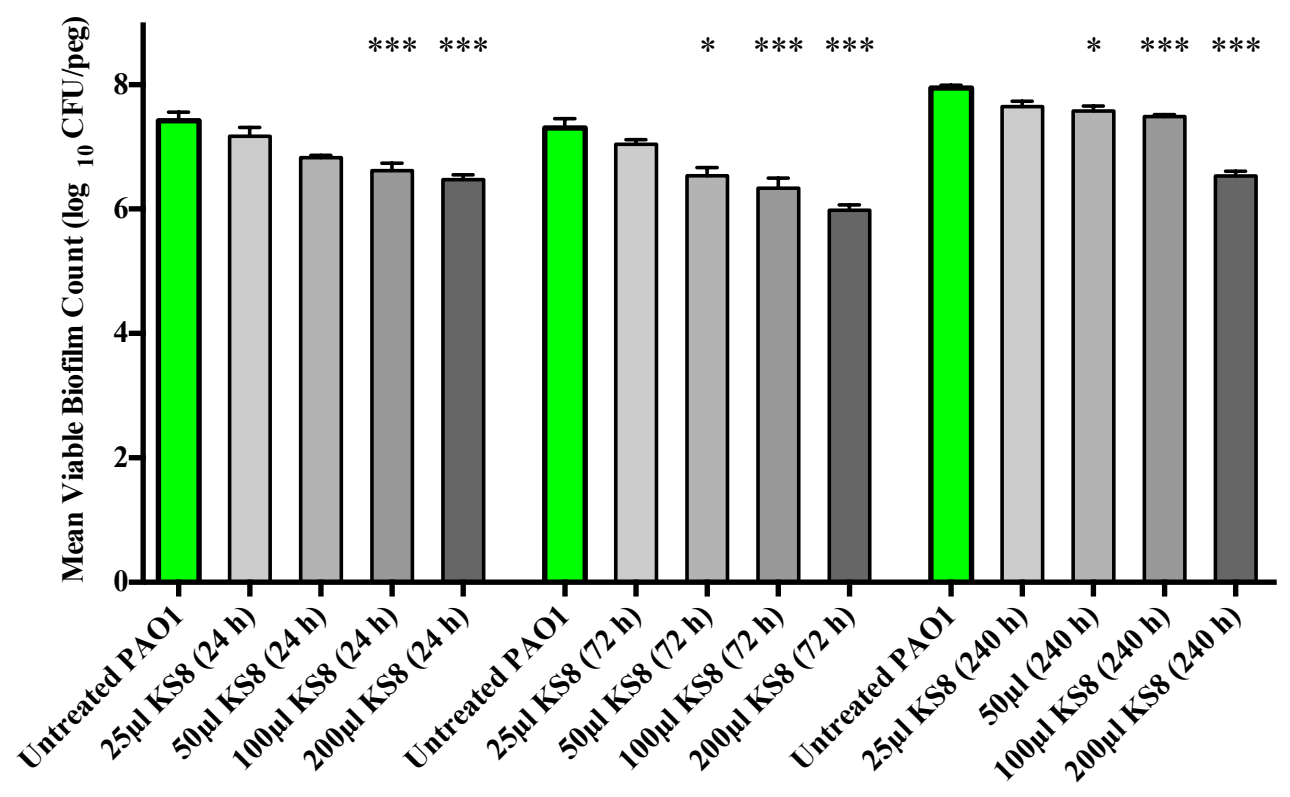

Figure 4. Prevention of biofilm formation by isolate KS8 supernatant and determination of the optimal incubation period for bioactive production. P. aeruginosa (PAO1) mean biofilm counts following $24 \mathrm{~h}$ exposure to sterile 1-day, 3-day and 10-day supernatants of isolate KS8. PAO1 biofilms were grown on the Calgary Biofilm Device for $24 \mathrm{~h}$ in LB broth at $37{ }^{\circ} \mathrm{C}$ and $150 \mathrm{rpm}$. Differences in mean absorbance were compared to the untreated control at each time-point and considered significant when $p<0.05$ (* $p<0.05$, ** $p<0.01, * * * p<0.001)$ according to the non-parametric Kruskal Wallis test with Dunn's Multiple Comparison Test.

The effect of KS8 supernatant on pre-established Pseudomonas aeruginosa PAO1 biofilms was examined by scanning electron microscopy (SEM) with the primary purpose of investigating the effect on cell integrity and the resulting morphological changes experienced by constituent cells, as well as effects on biofilm architecture as a whole. PAO1 biofilms treated with KS8 supernatant appeared to confirm the reduction in biomass absorbance and viable counts lacking the presence of copious exoploymeric matrix and the absence of a confluent lawn of biofilm growth (Figure 6).

To optimize the production of bioactives prior to solvent extraction of culture supernatants, the production of putative QSIs was determined across a range of temperatures and incubation times. The optimal incubation temperature for bioactive production was found to be $37{ }^{\circ} \mathrm{C}$ and the optimal cultivation time was found to be 3-10 days depending on the pathogen being challenged (Supplementary Figures S3 and S4). Disc diffusion assays using sterile supernatant failed to identify 
the presence of antibiotic activity against $P$. aeruginosa PAO1 suggesting the antibiofilm activity observed is not attributable to a bactericidal effect.

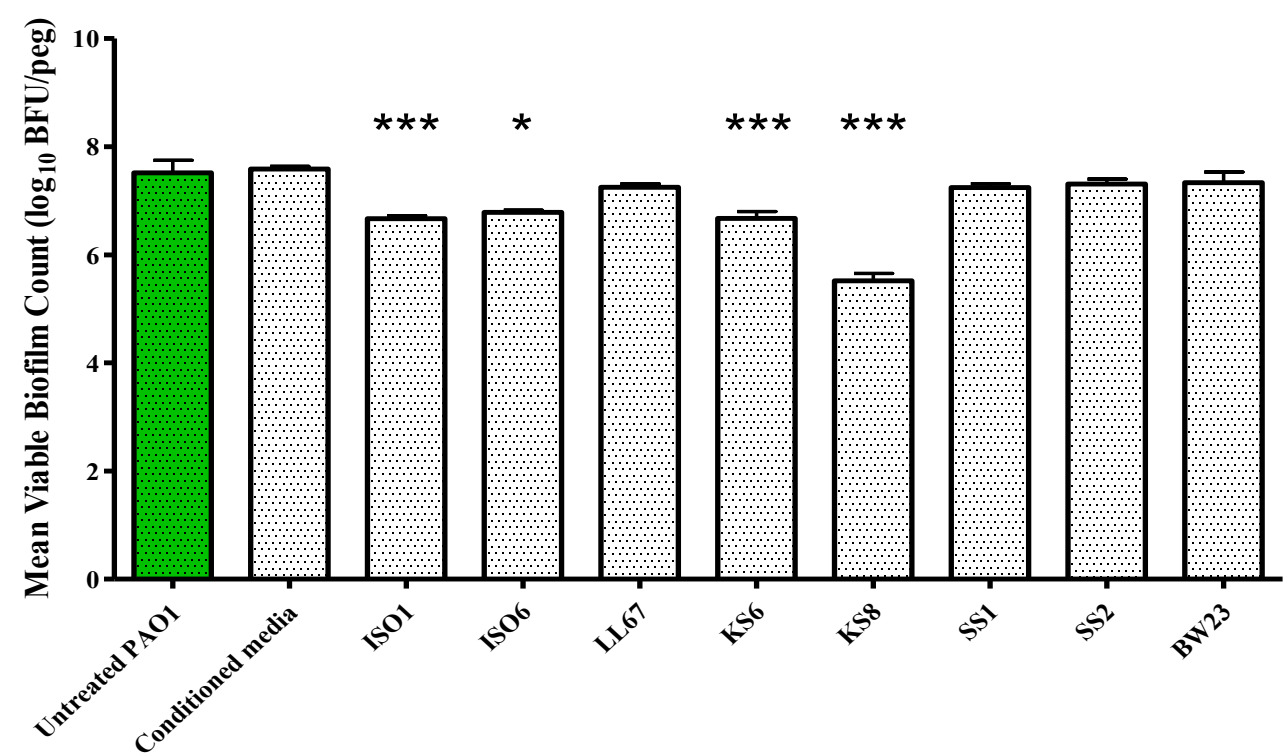

Figure 5. Biofilm eradication assay. $P$. aeruginosa PAO1 biofilms were grown on the Calgary Biofilm Device for $24 \mathrm{~h}$ in LB broth at $37^{\circ} \mathrm{C}$ and $150 \mathrm{rpm}$ prior to challenge. Mean viable biofilm counts obtained following $24 \mathrm{~h}$ exposure to $100 \mu \mathrm{L}$ of sterile 3 -day supernatant of isolates ISO1, ISO6, LL67, KS6, KS8, SS1, SS2, and BW23. Each value is expressed as the mean and standard deviation of at least six replicates. Differences in mean absorbance were compared to the untreated control at each time-point and considered significant when $p<0.05(* p<0.05, * * p<0.01, * * * p<0.001)$ according to the nonparametric Kruskal Wallis test with Dunn's Multiple Comparison Test.

Table 2. Biofilm eradication assay. $\log _{10} \mathrm{bfu} / \mathrm{peg}$ biofilm viable counts and percent reduction of pre-established $P$. aeruginosa (PAO1) biofilms challenged with $100 \mu \mathrm{L}$ of 3-day supernatant of marine isolate $\mathrm{KS} 8$ in the $\mathrm{CBD}\left(24 \mathrm{~h}\right.$ at $37{ }^{\circ} \mathrm{C}$ and $95 \%$ relative humidity at $150 \mathrm{rpm})$. Differences in $\log _{10}(\mathrm{bfu} / \mathrm{peg})$ were considered significant when $p<0.05(* p<0.05, * * p<0.01, * * * p<0.001)$ according to the non-parametric Kruskal Wallis test with Dunn's Multiple Comparison Test. Values for the percent reduction in biomass absorbance are also included.

\begin{tabular}{ccccc}
\hline & \multicolumn{2}{c}{ Biofilm Formation } & \multicolumn{2}{c}{ Biofilm Eradication } \\
\hline & $\begin{array}{c}\mathbf{L o g}_{10} \\
\text { bfu/peg }\end{array}$ & $\begin{array}{c}\Delta(\operatorname{Log10} \mathbf{b f u} / \mathbf{p e g}) \\
\text { and \% Reduction }\end{array}$ & $\begin{array}{c}\mathbf{L o g}_{10} \\
\text { bfu/peg }\end{array}$ & $\begin{array}{c}\Delta(\log 10 \text { bfu/peg) } \\
\text { and \% Reduction }\end{array}$ \\
\hline Untreated PAO1 & 7.30 & & 7.52 & \\
\multirow{2}{*}{ KS8 } & 6.34 & -0.96 & 5.52 & $-2.00(* * *)$ \\
& & $(-89.04 \%)$ & & $(-99.00 \%)$ \\
\hline
\end{tabular}




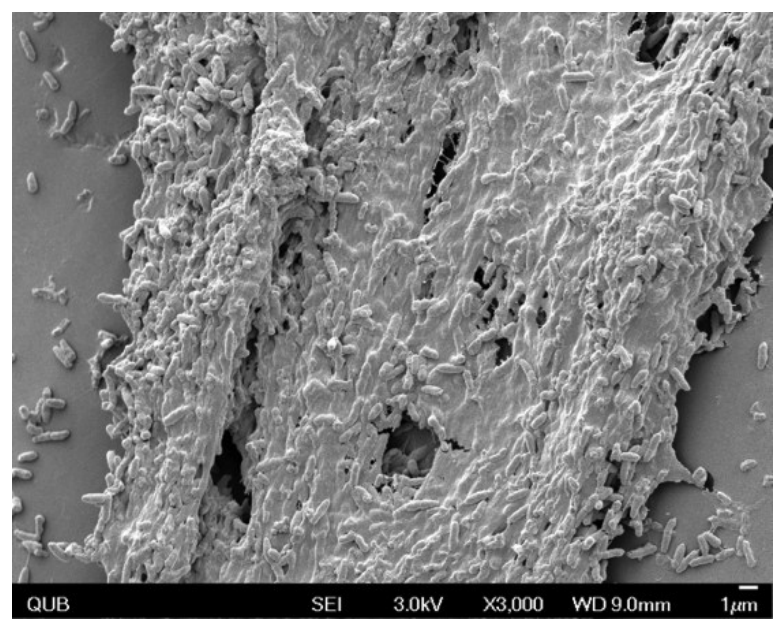

(A)

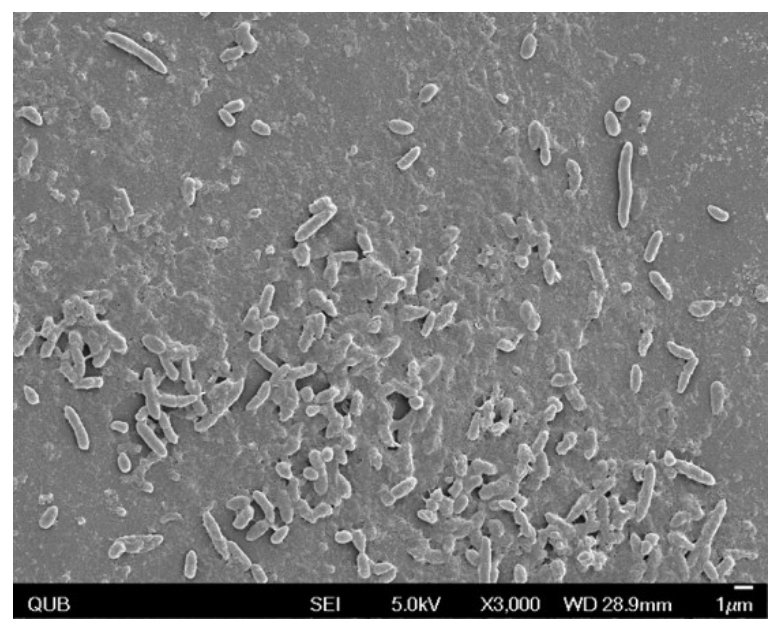

(B)

Figure 6. Scanning electron micrographs of (A) P. aeruginosa PAO1 biofilms grown on the $\mathrm{CBD}$ for $24 \mathrm{~h}$ at $37{ }^{\circ} \mathrm{C}$; (B) PAO1 biofilms treated with KS8 8-day supernatant. Pictures were taken using using a field emission scanning electron microscope FE-SEM (JEOL JSM-6500F FE-SEM, JEOL Ltd., Tokyo, Japan).

Solvent extraction was performed in an attempt to extract and concentrate the antibiofilm compounds produced by marine isolate KS8. Ethyl acetate extraction of supernatants is a standard technique routinely employed for the initial crude extraction of bioactives from microorganisms [70,71]. Growth curves of planktonic $P$. aeruginosa PAO1 treated with KS8 crude extract excluded growth inhibitory effects or antimicrobial effects at concentrations of the extract up to $1 \mathrm{mg} / \mathrm{mL}$ (Supplementary Figure S5). Moreover, screening of the organic crude extract of isolate KS8 against C. violaceum ATCC 12472 (Figure 7) and Serratia sp. ATCC 39006 using the disc diffusion assay confirmed the successful extraction of compounds with putative QSI activity. Heating the crude extract at $60{ }^{\circ} \mathrm{C}$ for $30 \mathrm{~min}$ did not affect the QSI activity displayed in the disc diffusion assay using C. violaceum ATCC 12472 (data not shown) suggesting the bioactive compound(s) involved are unlikely to be proteinaceous.

KS8 crude organic extract was tested for antimicrobial activity against a panel of Gram negative and Gram positive pathogens (Table 3). The crude organic extract of isolate KS8 displayed a selective antimicrobial activity against Gram negative pathogens inhibiting the growth of $P$. aeruginosa PAO1 $(\mathrm{MIC}=2 \mathrm{mg} / \mathrm{mL})$ and displaying a bactericidal activity against $E$. coli ATCC 11303 (MIC $=0.5 \mathrm{mg} / \mathrm{mL}$, $\mathrm{MBC}=4 \mathrm{mg} / \mathrm{mL})$ and P. mirabilis ATCC $7002(\mathrm{MIC}=1 \mathrm{mg} / \mathrm{mL}, \mathrm{MBC}=2 \mathrm{mg} / \mathrm{mL})$. Although the MBEC value of the crude extract of KS8 was found to be greater than $4 \mathrm{mg} / \mathrm{mL}$, a 2-log reduction (99\%) was observed against mature pre-established PAO1 biofilms. 


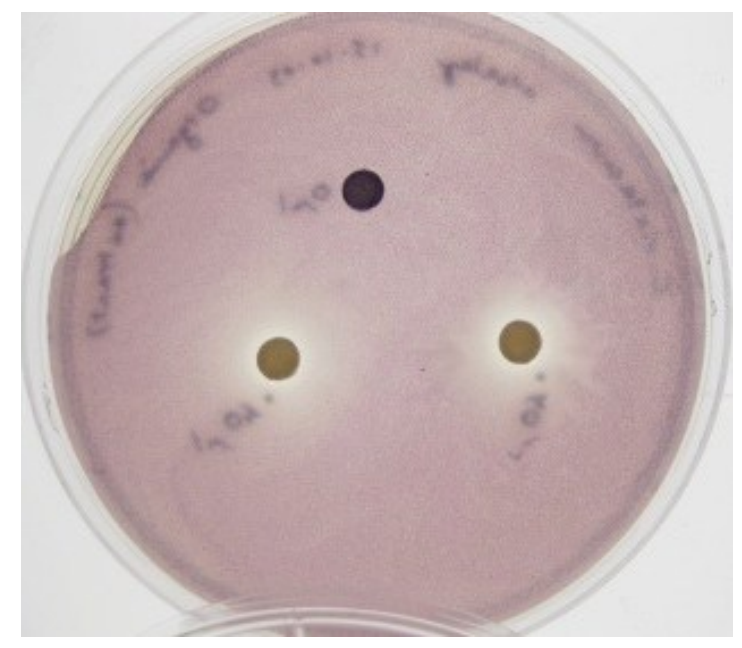

Figure 7. Disc diffusion assays on QSI-reporter strain C. violaceum ATCC 12472 using the crude organic extract of marine isolate KS8. A disc loaded with $60 \mu \mathrm{L}$ of EtOAc and allowed to air-dry was included in the plate as a solvent control (top). Two discs were loaded with $40 \mu \mathrm{L}$ of the crude organic extract of marine isolate KS8 $(10 \mathrm{mg} / \mathrm{mL})$. QSI activity was detected as an opaque halo surrounding the test discs.

The contribution of QS controlled factors (including toxA, lasA, lasB, rhamnolipids and pyocyanin) to the virulence of $P$. aeruginosa has been demonstrated by several previous studies [72]. $P$. aeruginosa produces a major siderophore (iron-chelating molecule) known as pyoverdine necessary for infection in several different disease models [73]. Pyoverdin is secreted in an apo-form and imported as ferric complexes of iron-binding proteins such as lactoferrin, transferrin and ferritin allowing P. aeruginosa to thrive in the iron-poor environment that is the host. Moreover, pyoverdine-dependent iron transport (iron as a cofactor for many metabolic enzymes) is also crucial for biofilm formation [74], highlighting the importance of monitoring the production of these siderophore to study $P$. aeruginosa pathogenesis. Pyocyanin is one of the numerous exotoxins produced and secreted by $P$. aeruginosa. It is a secondary metabolite with the ability to oxidize and reduce other molecules and is able to target a wide range of cellular components and pathways [75].

Table 3. Minimum inhibitory concentration (MIC), minimum bactericidal concentration (MBC) and minimum biofilm eradication concentration (MBEC) of the crude organic extract of marine isolate $\mathrm{KS} 8(\mathrm{mg} / \mathrm{mL})$ against a range of human pathogens associated to indwelling medical device infections.

\begin{tabular}{|c|c|c|c|c|c|c|c|c|c|}
\hline & PAO1 & $\begin{array}{c}E . \text { coli } \\
\text { ATCC } \\
11303 \\
\end{array}$ & $\begin{array}{c}P . \text { mir. } \\
\text { ATCC } \\
7002\end{array}$ & $\begin{array}{c}\text { S. aureus } \\
\text { ATCC } 29213\end{array}$ & $\begin{array}{c}\text { S. aureus } \\
\text { NCTC } \\
12981 \\
\end{array}$ & $\begin{array}{c}\text { S. aureus } \\
\text { ATCC } \\
43300 \\
\end{array}$ & $\begin{array}{c}\text { MRSA } \\
\text { ATCC } \\
\mathbf{3 3 5 9 3} \\
\end{array}$ & $\begin{array}{c}\text { S. epi. } \\
\text { NCTC } \\
13360\end{array}$ & $\begin{array}{c}\text { MRSE } \\
\text { NCTC } \\
11964 \\
\end{array}$ \\
\hline $\mathrm{MIC}(\mathrm{mg} / \mathrm{mL})$ & 2 & 0.5 & 1 & $>4$ & $>4$ & $>4$ & $>4$ & $>4$ & $>4$ \\
\hline $\mathrm{MBC}(\mathrm{mg} / \mathrm{mL})$ & $>4$ & 4 & 2 & $>4$ & $>4$ & $>4$ & $>4$ & $>4$ & $>4$ \\
\hline $\operatorname{MBEC}(\mathrm{mg} / \mathrm{mL})$ & $>4$ & $>4$ & $>4$ & $>4$ & $>4$ & $>4$ & n.a. & $>4$ & $>4$ \\
\hline
\end{tabular}

To understand whether the putative QSI activity of the crude extracts could affect the QS-dependent synthesis of virulence factors and exoproducts, the production of pyoverdin and pyocyanin by biofilms 
and their planktonic cultures challenged with KS8 supernatants was measured. The crude extract of isolate KS8 significantly decreased pyocyanin production at the highest concentration tested $(1 \mathrm{mg} / \mathrm{mL})(* * * p<0.001)$ (Figure $8 \mathrm{~A})$. The crude extract of isolate KS8 also significantly decreased the production of pyoverdin at the highest concentration tested $(1 \mathrm{mg} / \mathrm{mL})(* * * p<0.001)$ (Figure 8B). These results appear to confirm the QSI activity displayed by isolate KS8 on reporter strain Serratia $\mathrm{sp}$. ATCC 39006 suggesting the presence of molecules capable of interfering with the C4-HSL pathway of $P$. aeruginosa responsible for regulating pyocyanin and pyoverdin biosythesis.

When in the biofilm mode of growth, $P$. aeruginosa utilizes QS to control expression of tissue-damaging virulence factors, including proteases and rhamnolipids which function as a protective shield against the innate immune system causing necrosis of polymorphonuclear leucocytes (PMNs) [76]. $P$. aeruginosa biofilms of mutants lacking a functional QS system have shown to be more susceptible to tobramycin in vitro supporting the validity of using QSIs in combination to tobramycin to eradicate biofilm-related infections [15]. The synergistic antimicrobial efficacy obtained by combining KS8 crude organic extract and tobramycin produced a 10-fold decrease in the MIC concentration of tobramycin (from $0.75 \mu \mathrm{g} / \mathrm{mL}$ to $0.075 \mu \mathrm{g} / \mathrm{mL}$ ) against $P$. aeruginosa PAO1 (Figure 9). Although the enhanced antimicrobial efficacy remains to be tested in vivo, the results suggest that an early, combined treatment strategy for chronic infections using putative QSIs produced by KS8 in combination with tobramycin prophylactically or at an early stage of infection could result in an increased clearance of $P$. aeruginosa, making this strain an ideal candidate for the isolation of novel antibiofilm QSI compounds for the attenuation of virulence and increased antimicrobial susceptibility of $P$. aeruginosa.

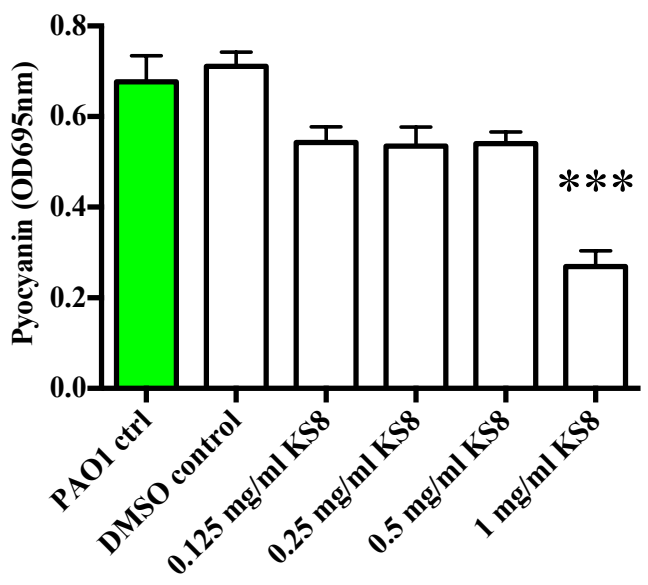

(A)

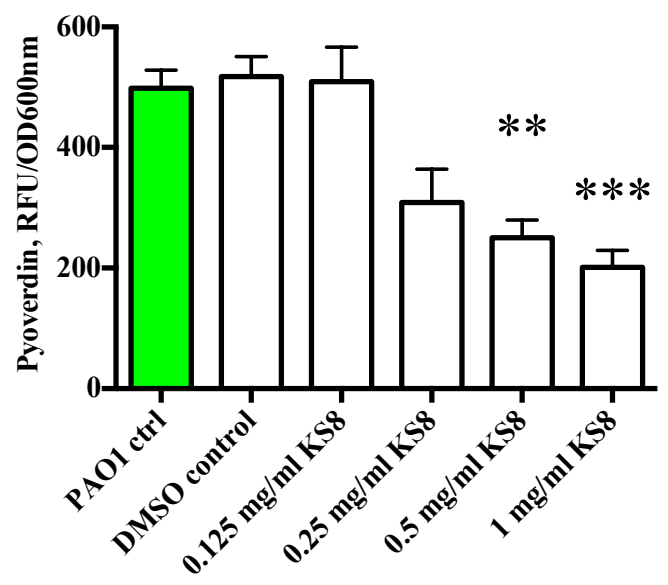

(B)

Figure 8. (A) Production of Pyocyanain (OD695 nm) by P. aeruginosa (PAO1) $48 \mathrm{~h}$ biofilms and planktonic cultures following $24 \mathrm{~h}$ treatment with KS8 crude organic extract. (B) Production of the QS-controlled siderophore Pyoverdine (Excitation $400 \mathrm{~nm}$ emission $450 \mathrm{~nm} / \mathrm{OD} 600 \mathrm{~nm}$ )) by $P$. aeruginosa (PAO1) $48 \mathrm{~h}$ biofilms and planktonic cultures following $24 \mathrm{~h}$ treatment with KS8 crude organic extract. Differences in mean absorbance were compared to the untreated control at each time-point and considered significant when $p<0.05$ (* $p<0.05, * * p<0.01, * * * p<0.001)$ according to the non-parametric Kruskal Wallis test with Dunn's Multiple Comparison Test. 


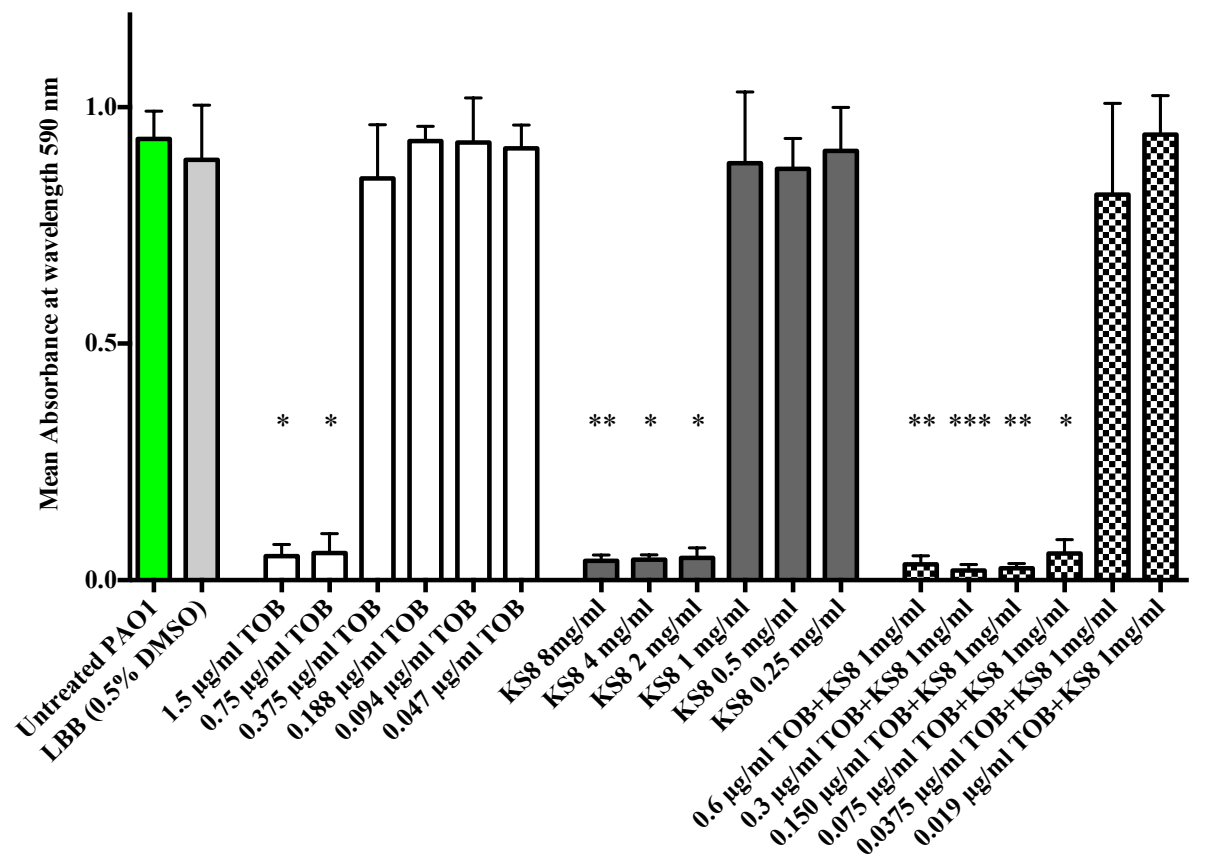

Figure 9. Enhanced antimicrobial activity of tobramycin when used in combination with KS8 organic extract against planktonic cultures of $P$. aeruginosa PAO1. The MIC value of tobramycin against PAO1 was determined to be $0.75 \mu \mathrm{g} / \mathrm{mL}$. The MIC value of KS8 extract was determined to be $2.0 \mathrm{mg} / \mathrm{mL}$. The MIC value of tobramycin used in combination with KS8 organic extract $(1 \mathrm{mg} / \mathrm{mL})$ was $0.075 \mu \mathrm{g} / \mathrm{mL}$, a ten-fold decrease when compared to the MIC of tobramycin alone. DMSO in LB broth $(0.5 \% \mathrm{w} / \mathrm{v})$ was used as solvent control. Differences in mean absorbance were compared to the untreated control at each time-point and considered significant when $p<0.05\left({ }^{*} p<0.05,{ }^{* *} p<0.01,{ }^{* * *} p<0.001\right)$ according to the non-parametric Kruskal Wallis test with Dunn's Multiple Comparison Test.

In this study, a marine Pseudoalteromonas sp. isolate was found to produce putative QSIs active against $P$. aeruginosa PAO1. The supernatant of isolate KS8 caused a significant decrease in both biofilm biomass and viable counts during $P$. aeruginosa biofilm formation and eradication. KS 8 extract also caused a significant decrease in the production of pyoverdin and pyocyanin in $P$. aeruginosa biofilm cultures treated with KS8 supernatant supporting the role of QSIs in the antibiofilm activities observed. The efficacy of a combinatorial treatment using tobramycin and KS8-derived QSIs against $P$. aeruginosa PAO1 was investigated in vitro, further validating the strategy based on combining QSIs with sub-therapeutic concentrations of conventional antimicrobial agents. Isolate KS8 remains an ideal candidate for the purification and characterization of QSIs with clinical relevance.

\section{Experimental Section}

\subsection{Bacterial Strains Used in This Study}

The test pathogens used in this study are Pseudomonas aeruginosa (PAO1), Staphylococcus epidermidis NCTC 13360, S. epidermidis NCTC 11964, Staphylococcus aureus ATCC 29213, S. aureus ATCC 33593, S. aureus ATCC 43300, S. aureus NCTC 12981, Escherichia coli ATCC 11303, and P. mirabilis ATCC 7002. 
C. violaceum ATCC 12472 (cultured in Luria Bertani (LB) broth at $37^{\circ} \mathrm{C}$ ), C. violaceum CV026 (cultured in Luria Bertani (LB) broth at $37{ }^{\circ} \mathrm{C}$ and maintained in kanamycin $25 \mu \mathrm{g} / \mathrm{mL}$ ) and Serratia sp. ATCC 39006 (cultured in LB broth at $26^{\circ} \mathrm{C}$ ) were used as QSI reporter strains. B. cereus NCTC 9945 harboring the aiiA lactonase gene was used as QSI positive control. All strains used in this study were stored in LB broth supplemented with $15 \%$ glycerol at $-80{ }^{\circ} \mathrm{C}$.

\subsection{Sampling and Isolation of Bacterial Epiphytes}

A variety of marine samples including seaweeds and seagrasses, invertebrates, sediment and sea water were collected in the rockpools in the intertidal zone of 6 different sampling sites along the coast of Ireland (Co. Donegal) and Northern Ireland (Co. Down). Specimens were collected at low tide, trying to avoid heavy perturbance of the surrounding sediments and using sterile gloves and a sterile scalpel. Specimens were collected in sterile $50 \mathrm{~mL}$ tubes (BD Falcon ${ }^{\mathrm{TM}} 50 \mathrm{~mL}$ conical centrifuge tubes) or small sterile plastic bags containing seawater prior to removal from the rockpool in order to avoid contact with air. Each sample was kept individually in either $50 \mathrm{~mL}$ tubes or plastic bags and stored on ice until processing within a few hours from collection. A portion of each sample was immediately used for the isolation of surface-associated bacteria (within $3 \mathrm{~h}$ after arrival at the laboratory).

In order to remove any non-specific, loosely attached and planktonic bacteria prior to the isolation of surface associated epibionts, each eukaryotic specimen (or a section thereof) was placed in a $50 \mathrm{~mL}$ conical centrifuge tube with $30 \mathrm{~mL}$ of sterile sea water (SSW), vortexed vigorously for $30 \mathrm{~s}$ and the supernatant discarded. The process was repeated three times. Rinsed specimens were placed in sterile Petri dishes and manipulated using sterile forceps. A sterile cotton swab was used to collect bacterial epiphytes from the samples' surfaces and was then placed in $30 \mathrm{~mL}$ of Marine Broth (MB) in $50 \mathrm{~mL}$ conical centrifuge tubes. Inoculated tubes were incubated at $4{ }^{\circ} \mathrm{C}$, room temperature $\left(\mathrm{rt}, 30{ }^{\circ} \mathrm{C}\right), 37^{\circ} \mathrm{C}$ and $55{ }^{\circ} \mathrm{C}$ and examined at regular $24 \mathrm{~h}$-intervals for growth. Once growth was evident in the inoculated tubes, serial dilutions to $10^{-7}$ in MB were prepared and plated on Marine agar (MA), LB agar (LBA), Skim Milk agar (SMA), Low Swarm agar (LSWA) and Blood Agar (BA) plates and incubated at $4{ }^{\circ} \mathrm{C}, \mathrm{rt}, 30^{\circ} \mathrm{C}, 37^{\circ} \mathrm{C}$ and $55^{\circ} \mathrm{C}$ for up to three weeks.

All isolation plates were examined daily for the first week and weekly thereafter. Colonies showing different morphologies (color, texture, shape, size) under the different selective conditions were picked and purified by re-streaking as required on the media used for the isolation. Pure bacterial cultures were stored at $-80{ }^{\circ} \mathrm{C}$ using the Microbank ${ }^{\mathrm{TM}}$ long term storage system (Pro-Lab Diagnostics, Neston, Wirral, UK) as per manufacturer's guidelines, in triplicate. All isolates were further characterized by examining optimal growth temperature $\left(4^{\circ} \mathrm{C}, \mathrm{rt}, 30^{\circ} \mathrm{C}, 37^{\circ} \mathrm{C}\right.$ and $\left.55^{\circ} \mathrm{C}\right)$ and media (MA, LBA, SMA, LSWA and BA), subjecting them to Gram stain, and screening for haemolytic activity on BA, caseinolytic activity on SMA and catalase production using $3 \% \mathrm{H}_{2} \mathrm{O}_{2}$ prior to $16 \mathrm{~S}$ rRNA gene sequencing.

\section{3. $16 S$ rRNA Gene Sequencing and Bacterial Identification}

Identification of isolates was achieved through $16 \mathrm{~S}$ rRNA gene sequencing. Total DNA was extracted using the GenElute ${ }^{\circledR}$ Bacterial Genomic DNA kit NA2110-1KT (Sigma Aldrich, Poole, Dorset), as per manufacturer's guidelines. PCR was used to perform the amplification of the bacterial 16S rRNA gene using the 27F forward primer (5'-AGA GTT TGA TCM TGG CTC AG-3') and the 
1492R reverse primer (5'-TAC GGY TAC CTT GTT ACG ACT T-3') [77]. The concentration of each DNA sample was measured using the Qubit ${ }^{\circledR}$ Fluorometer (Invitrogen, Paisley, UK) and diluted to $0.5 \mu \mathrm{g} / \mu \mathrm{L}$. PCR reactions were prepared by adding $2 \mu \mathrm{L}$ of genomic DNA sample, $5 \mu \mathrm{L}$ of primer $27 \mathrm{~F}$ $(2.5 \mathrm{mM})$ and $5 \mu \mathrm{L}$ of primer $1492 \mathrm{R}(2.5 \mathrm{mM})$ to $25 \mu \mathrm{L}$ of DreamTaq ${ }^{\circledR}$ Master Mix (Fermentas, Roskilde, Denmark) and $13 \mu \mathrm{L}$ of double-distilled water (DDW) (total reaction volume $50 \mu \mathrm{L}$ ). A negative control containing additional $2 \mu \mathrm{L}$ of DDW instead of DNA was prepared. The 16S rRNA gene fragments were amplified using the I-Cycler ${ }^{\mathrm{TM}}$ thermocycler (BioRad, Hertfordshire, UK) using the following parameters: initial denaturing step at $94{ }^{\circ} \mathrm{C}$ for $3 \mathrm{~min}$, 30 cycles of denaturing temperature at $94{ }^{\circ} \mathrm{C}$ for $1 \mathrm{~min}$ followed by an annealing temperature of $53{ }^{\circ} \mathrm{C}$ for $1 \mathrm{~min}$ and extension at $72{ }^{\circ} \mathrm{C}$ for $1 \mathrm{~min}$, followed by a final single extension step of $72{ }^{\circ} \mathrm{C}$ for $10 \mathrm{~min}$. The products from the amplification were then purified using the Pure Link PCR purification kit (Invitrogen, Paisley, UK), according to the manufacturer's protocol. Gel electrophoresis using a $1 \% \mathrm{w} / \mathrm{v}$ agarose gel (Invitrogen, Paisley, UK) was carried out on both PCR products and purified PCR products in order to determine quality, concentration and verify the size of the amplicons. The concentration of each purified sample was measured using the Qubit ${ }^{\circledR}$ Fluorometer (Invitrogen, Paisley, UK) and diluted to a concentration of $10 \mathrm{ng} / \mu \mathrm{L}$ prior to sequencing. Sequencing was carried out by Eurofins MWG Operon (London, UK) with a Roche GS FLX sequencer using the $27 \mathrm{~F}$ primer. Several strains were further sequenced using the $1492 \mathrm{R}$ primer in order to improve identification. Sequence data were analyzed by comparison with the 16S rRNA gene sequences available in the National Center for Biotechnology Information (NCBI) GenBank database. Isolate identification was performed using the BLASTn server tool.

\subsection{Antimicrobial Screening Assays}

The disc diffusion susceptibility method was performed according to the method described by Bauer et al. [78] and used to screen supernatants and the crude organic extracts of isolate KS8 for the presence of antimicrobial compounds against Escherichia coli ATCC 11303, Pseudomonas aeruginosa PAO1 and Proteus mirabilis ATCC 7002. Antimicrobial activity was quantified by modifying the paper disc diffusion procedure described by Assefa et al. [79]. The antibiotic susceptibility of isolate KS8 was determined using Oxoid M.I.C.Evaluator ${ }^{\mathrm{TM}}$ (M.I.C.E ${ }^{\mathrm{TM}}$; Thermo Fisher Scientific, Waltham, MA, USA) [80].

\subsection{Screening for the Production of QSI}

Chromobacterium violaceum ATCC 12472 (cultured in LB broth at $37{ }^{\circ} \mathrm{C}$ ), C. violaceum CV026 (cultured at $28{ }^{\circ} \mathrm{C}$ in $\mathrm{LB}$ broth supplemented with Kanamycin $25 \mu \mathrm{g} / \mathrm{mL}$ ), and Serratia sp. ATCC 39006 (cultured in LB broth at $26^{\circ} \mathrm{C}$ ) were used to screen for the presence of QSI activity. Screening for the production of QSIs was carried out according to the protocol described by McLean et al. [81]. Marine isolates were streaked on LB agar plates and incubated at $28{ }^{\circ} \mathrm{C}$ for 24-48 h. Plates were then overlaid with $10 \mathrm{~mL}$ of $0.5 \% \mathrm{LB}$ agar $\left(47^{\circ} \mathrm{C}\right)$ inoculated with $5 \mu \mathrm{L}$ of an overnight culture of $C$. violaceum (ATCC 12474) or $5 \mu \mathrm{L}$ of an overnight culture of Serratia sp. (ATCC 39006) or $10 \mathrm{~mL}$ of $0.5 \%$ LBA $5 \mu \mathrm{M} \mathrm{N}$-(3oxo-hexanoyl)-DL-homoserine lactone (3OC6HSL) (Sigma Aldrich, Poole, Dorset) inoculated with $50 \mu \mathrm{L}$ of an overnight culture of CV026. Plates were 
incubated overnight at $37{ }^{\circ} \mathrm{C}, 28{ }^{\circ} \mathrm{C}$ or $26^{\circ} \mathrm{C}$ depending on the reporter strain being used. Following overnight incubation, the presence of an opaque halo (growth of reporter strain with pigment inhibition) surrounding the isolate being screened was considered indicative of putative QSI activity. Growth inhibition of the indicator culture (the presence of a clear halo surrounding the isolate being screened) was considered indicative of possible antimicrobial activity.

\subsection{Preparation of Culture Supernatants and "Conditioned Media"}

Microbank $^{\mathrm{TM}}$ long-term preserver beads (Pro-Lab Diagnostics, Neston, Wirral, UK) were used to streak LBA plates with the marine isolates to be tested. Single colonies were picked and used to inoculate $100 \mathrm{~mL}$ of LB broth in glass flasks. Flasks were incubated at rt, $28{ }^{\circ} \mathrm{C}$ or $37^{\circ} \mathrm{C}$ at $100 \mathrm{rpm}$ in a gyrorotary incubator and left for the required amount of time (1, 3, 6, 9 or 10 days). The cultures were then centrifuged at $4000 \mathrm{rpm}$ for $30 \mathrm{~min} .15 \mathrm{~mL}$ aliquots of the cell-free cultures were then transferred to a $20 \mathrm{~mL}$ syringe and sterilised using $0.45 \mu \mathrm{m}$ and $0.20 \mu \mathrm{m}$ pore size filters in series (Millipore, Carrigtwohill, Ireland). A volume of 30-45 mL of each supernatant was collected in sterile tubes and stored at $-20^{\circ} \mathrm{C}$.

In order to verify the impact of using nutrient-depleted supernatants to study antibiofilm activity on different test strains, conditioned media (CM), consisting of the sterile supernatant of the different test strains (E. coli, P. mirabilis and P. aeruginosa) grown in LB broth for different amounts of time was prepared as described above and used as a control where appropriate.

\subsection{Biofilm Formation Assay}

To measure the biomass produced (biofilm formation) by E. coli, P. mirabilis and P. aeruginosa in the presence of the sterile supernatants of the marine isolates, test biofilms were grown in 96-well microtitre plates using the method described by Stepanovic et al. [82], with slight modifications. Overnight inoculums of test strains were diluted to a 0.5 McFarland standard (approx. OD 0.3, $550 \mathrm{~nm}$ ), using quarter strength Ringer's solution (QSRS) corresponding to a total planktonic viable count of approximately $1.5 \times 10^{8}$ colony forming units per milliliter $(\mathrm{CFU} / \mathrm{mL})$. The inocula were further diluted to $3 \times 10^{6} \mathrm{CFU} / \mathrm{mL}$ (verified by Miles and Misra viable count [83]). $100 \mu \mathrm{L}$ of the inoculum of each test pathogen was placed in columns $2-12$ of a 96 -well microtitre plate. $200 \mu \mathrm{L}$ of LB broth were placed in column 1 as a sterility control. $100 \mu \mathrm{L}$ of filter sterilised supernatants of the marine bacterial isolates were placed in columns $4-12$ of the 96 -well microtitre plates. $100 \mu \mathrm{L}$ of LB broth were added to column two as an untreated control. In order to verify the effect of nutrient depletion on biofilm formation, $100 \mu \mathrm{L}$ of conditioned media (CM) was added to column three as an additional control. Plates were incubated and biofilms allowed to grow for $24 \mathrm{~h}$ at $37{ }^{\circ} \mathrm{C}$ and $95 \%$ relative humidity and $150 \mathrm{rpm}$ in a gyrorotary incubator. Following exposure to spent supernatants for $24 \mathrm{~h}$, the adherent biomass of each well was washed three times with $280 \mu \mathrm{L}$ of PBS solution to remove planktonic bacteria. The biofilms were then fixed by adding $250 \mu \mathrm{L}$ of $\mathrm{MeOH}$ and incubating at room temperature for $30 \mathrm{~min}$. The methanol was then discarded and the plates allowed to air dry for 10 min under a laminar air hood. Being careful to avoid staining the thick air liquid interface, $180 \mu \mathrm{L}$ of $0.1 \%(\mathrm{w} / \mathrm{v})$ crystal violet solution in $70 \%$ ethanol were added to each well and left for $5 \mathrm{~min}$ at $\mathrm{rt}$. The crystal violet solution was then discarded and the plates rinsed 3 times with $300 \mu \mathrm{L}$ of $0.9 \%$ saline 
solution making sure that no excess unbound crystal violet had remained. The plates were then allowed to air-dry for $15 \mathrm{~min}$. Finally, the stain bound to the biofilm matrix was re-solubilised with a mixture of $80 \% \mathrm{EtOH}$ and $20 \%$ acetone. The mean absorbance of the biofilm biomass was measured at $590 \mathrm{~nm}$ using a Tecan Sunrise ${ }^{\circledR}$ plate reader (Männedorf, Switzerland). Each crystal violet assay was run in triplicate, with a minimum of 6 replicates per assay.

\subsection{Biofilm Removal Assay}

The Calgary Biofilm Device (CBD) (available as the MBEC AssayTM for Physiology \& Genetics (P\&G), Innovotech Inc., Edmonton, Alberta, Canada) was used to evaluate the effect of filter-sterilised supernatants on the biomass of pre-established $24 \mathrm{~h}$ biofilms of test pathogens. The wells of the CBD were inoculated with $200 \mu \mathrm{L}$ of a $3 \times 10^{6} \mathrm{CFU} / \mathrm{mL}$ inoculum of test strains prepared as previously described. LB broth was included in each assay as a sterility control. The MBEC assay plates (Innovotech Inc., AB, Canada) were transferred to a gyrorotary incubator $\left(37{ }^{\circ} \mathrm{C}, 95 \%\right.$ relative humidity) for $24 \mathrm{~h}$ to allow growth of test biofilms. A separate challenge plate was inoculated with $200 \mu \mathrm{L}$ of isolates' supernatants diluted in LB broth (50:50 v/v). LB broth was included in each assay plate as a sterility control and to provide an untreated control. The effect of nutrient depletion was determined growing each test strain in a mixture of conditioned media (CM) and LB broth (50:50 v/v). Following $24 \mathrm{~h}$ of incubation, the lid of the CBD was rinsed three times by immersing the pegs in three separate 96-well plates containing $250 \mu \mathrm{L}$ of QSRS. The lid with was then placed on the corresponding challenge plates and incubated at $37{ }^{\circ} \mathrm{C}$ and $95 \%$ relative humidity and $150 \mathrm{rpm}$ in a gyrorotary incubator for $24 \mathrm{~h}$. Following exposure of test biofilms to the supernatants for $24 \mathrm{~h}$, biofilms were rinsed with QSRS, fixed with methanol, air-dried and stained by immerging the lid in a 96-well plate containing $180 \mu \mathrm{L}$ of $0.1 \%$ crystal violet solution per well. Finally, the stain bound to the biofilm matrix was re-solubilized in a 96-well plate containing $200 \mu \mathrm{L}$ of a mixture of ethyl acetate EtOH and acetone (4:1). The mean absorbance of the biofilm biomass was measured at $590 \mathrm{~nm}$ using a Tecan Sunrise $^{\circledR}$ plate reader (Männedorf, Switzerland). Each assay was run in triplicate, with a minimum of 6 replicates per assay.

\subsection{Preparation of Crude Culture Extracts}

A volume of $1 \mathrm{~mL}$ of an overnight culture of marine isolate KS8 was used to inoculate individual glass flasks containing $1 \mathrm{~L}$ of LB broth. Flasks were incubated at rt, 28 or $37^{\circ} \mathrm{C}$ with constant shaking at $150 \mathrm{rpm}$ in a gyrorotary incubator. Following incubation for 1, 3, 6, 8 or 10 days, the $1 \mathrm{~L}$ cultures were extracted three times with $1 \mathrm{~L}$ of EtOAc at rt. Each extraction was performed in $2.5 \mathrm{~L}$ bottles placed on a horizontal shaker at $200 \mathrm{rpm}$ for $1 \mathrm{~h}$. The resulting two phases were separated and recovered using a separating funnel, and the extraction repeated. The combined organic phases of each supernatant $(3 \mathrm{~L})$ were dried using a rotary evaporator Rotavapor (R-114, Büchi, UK) at a temperature of no more than $37^{\circ} \mathrm{C}$. Dried extracts were stored at $-20^{\circ} \mathrm{C}$. 


\subsection{QSI Disc Diffusion Assay}

The QSI disc diffusion assays on test strains were performed using sterile supernatants and the organic extracts. Dried organic extracts were re-solubilized in EtOAc to yield solutions of $10 \mathrm{mg} / \mathrm{mL}$. The re-solubilized solutions were pipetted onto sterile paper disks $6 \mathrm{~mm}$ in diameter (Whatman, UK) by transferring a maximum of $10 \mu \mathrm{L}$ volumes at a time to achieve the desired test concentrations. Air-drying was allowed between multiple loadings. A disc loaded with $100 \mu \mathrm{L}$ of solvent (EtOAc unless otherwise specified) and allowed to air dry was also included as a negative control. The LBA plates were then overlaid with $10 \mathrm{~mL}$ of $0.5 \%$ LBA inoculated with $5 \mu \mathrm{L}$ of an overnight culture of C. violaceum (ATCC 12474) or $10 \mathrm{~mL}$ of $0.5 \%$ LBA $5 \mu \mathrm{M} \mathrm{N}$-(3oxo-hexanoyl)-DL-homoserine lactone (3OC6HSL) (Sigma Aldrich, Poole, Dorset) inoculated with $50 \mu \mathrm{L}$ of an overnight culture of CV026. Plates were incubated overnight at $37{ }^{\circ} \mathrm{C}$ for $24 \mathrm{~h}$ before being examined for the presence of opaque halos indicating QSI inhibition or clear halos indicating antimicrobial activity.

\subsection{MIC/MBC Determination}

Broth microdilution tests were carried out based on the protocol described in the NCCLS guidelines [84], with slight modifications. Crude organic extracts were re-solubilized in DMSO and a working solution of each extract to be tested was prepared in LB broth $(0.5 \%$ DMSO) and sterilized using a $0.22 \mu \mathrm{m}$ filter. From this stock solution, serial two-fold dilutions in LB broth were carried out in 96-well microtitre plates over the concentration range $8-0.0078 \mathrm{mg} / \mathrm{mL}$. A control using LB broth with $0.5 \%$ DMSO was also included in each broth microdilution assay.

\subsection{Screening for Antibiofilm Activity}

To test the effect of the filter-sterile supernatants or the crude organic extracts of the marine isolates on the viability of both biofilm and planktonic cultures during both biofilm formation and biofilm eradication (of mature biofilms) of test strains P. aeruginosa PAO1, E. coli ATCC 11303 and P. mirabilis ATCC 7002, the original MBEC protocol [85] was modified in order to generate three different sets of data including viable biofilm counts, MIC and MBEC values. Test strains were grown overnight in LB broth at $37^{\circ} \mathrm{C}$ and then subsequently diluted to obtain a culture of $0.3 \mathrm{OD}$ at $550 \mathrm{~nm}$ and further adjusted to provide a final inoculum density of $\sim 10^{7} \mathrm{CFU} / \mathrm{mL}$ (confirmed by viable counts). The biofilms of each test organism were grown in the Calgary Biofilm Device (Innovotech Inc., Edmonton, AL, Canada).

\subsubsection{Anti-Adherence Assay-Viable Counts}

An MBEC plate was inoculated as follows: column 1 containing $200 \mu \mathrm{L}$ of LB broth (blank), column 2 containing $100 \mu \mathrm{L}$ of LB broth and $100 \mu \mathrm{L}$ of test inoculum (negative control), column 3 containing $100 \mu \mathrm{L}$ of conditioned media when testing supernatants or $100 \mu \mathrm{L}$ of media with solvent control $(0.5 \%$ DMSO) when testing crude extracts and $100 \mu \mathrm{L}$ of test inoculum, and columns $4-12$ containing $100 \mu \mathrm{L}$ of the marine isolate's supernatant or crude extract in LB broth together with $100 \mu \mathrm{L}$ of test strain inoculum. Plates were incubated and biofilms allowed to grow for $24 \mathrm{~h}$ at $37^{\circ} \mathrm{C}$ and $95 \%$ relative humidity and $100 \mathrm{rpm}$ in a gyrorotary incubator. 
Following $24 \mathrm{~h}$ of incubation the plate was removed from the incubator and the lid of the 96 well plate was rinsed to remove planktonic bacteria by placing it into two fresh plates containing $250 \mu \mathrm{L}$ of sterile saline solution $(0.9 \%)$ per well for $1 \mathrm{~min}$. After rinsing the biofilms, four pegs were broken off from each of the test columns using sterile pliers and placed in the wells of the top row of a fresh 96 well plate containing $200 \mu \mathrm{L}$ of sterile saline $(0.9 \%)$ solution per well. The plate was then sonicated for $20 \mathrm{~min}$, an interval of time previously optimized and shown not to reduce $P$. aeruginosa PAO1, E. coli ATCC 11303 and P. mirabilis ATCC 7002 viability, using a Branson 3510 ultrasonic cleaner (40 KHz, 130-335 W) (Branson, Danbury, CT, USA). Following sonication, the pegs were discarded and each sample was serially diluted to $10^{-11}$. Each sample dilution was then plated using the Miles and Misra technique [83] and incubated overnight at $37^{\circ} \mathrm{C}$. The growth of the test strains' biofilms on the pegs was expressed as biofilm forming units per peg (BFU/peg).

\subsubsection{Screening for Antibiofilm Compounds with Biofilm Eradication Activity (MBEC)-Viable Counts}

The MBEC assay was conducted using KS8 organic extract prepared as for the MIC tests, as previously described. The wells of the CBD were inoculated with $200 \mu \mathrm{L}$ of a $3 \times 10^{6} \mathrm{CFU} / \mathrm{mL}$ inoculum of test strains prepared as previously described. The MBEC assay plates were transferred to a gyrorotary incubator $\left(37{ }^{\circ} \mathrm{C}, 95 \%\right.$ relative humidity) for $24 \mathrm{~h}$ to allow growth of test biofilms. Biofilm viable counts (BFU/peg) at $24 \mathrm{~h}$ were measured. Following the $24 \mathrm{~h}$ growth period, the peg lid of the MBEC assay plate was transferred to a rinse plate and each peg gently rinsed three times by immersion in wells containing $300 \mu \mathrm{L}$ sterile PBS.

After rinsing, the lid was transferred to a challenge plate containing serial doubling dilutions of KS8 extract over the concentration range of $4-0.0156 \mathrm{mg} / \mathrm{mL}$ (final volume $200 \mu \mathrm{L}$ ). LB broth and DMSO in LB broth $(0.5 \% \mathrm{w} / \mathrm{v})$ were used as negative and solvent control. The MBEC assay plates were transferred to a gyrorotary incubator $\left(37^{\circ} \mathrm{C}, 95 \%\right.$ relative humidity) for $24 \mathrm{~h}$. Following exposure of the biofilms for $24 \mathrm{~h}$ the lid with the pegs was removed from the challenge plate and rinsed three times in $300 \mu \mathrm{L}$ of sterile PBS. After rinsing, four pegs were broken off from each of the test columns and used to determine biofilm viable counts. The lid with the remaining pegs was transferred to a "recovery" plate containing LB broth. Biofilms were sonicated for $5 \mathrm{~min}$ and the peg lid discarded. The recovery plate was incubated overnight and checked visually after $24 \mathrm{~h}$ for turbidity. An MBEC value was assigned as the lowest concentration at which no growth was observed after $24 \mathrm{~h}$ incubation.

\subsection{Measurement of Siderophore (Pyoverdin) and Exoproduct (Pyocyanin) Production}

Pyoverdin production by $P$. aeruginosa PAO1 biofilms was measured according to the protocol described by Romanowski et al. [86], with slight modifications. An MBEC device was inoculated with PAO1 (inoculum density of $\sim 10^{7} \mathrm{CFU} / \mathrm{mL}$, as confirmed by viable count, $200 \mu \mathrm{L} /$ well) and biofilms were allowed to develop for $24 \mathrm{~h}$ at $37^{\circ} \mathrm{C}$ in LB broth. Following $24 \mathrm{~h}$ incubation, the MBEC lid with the $24 \mathrm{~h}$ biofilms was rinsed three times by placing it into three separate 96 -well plates each with $250 \mu \mathrm{L}$ of PBS in each well. Following rinsing, the lid was transferred to black, clear bottom 96-well plates (Corning Incorporated, Corning, NY, USA) containing the treatment to be applied. Following $24 \mathrm{~h}$ incubation with extracts, pyoverdin production was measured by fluorescence (ex $400 \mathrm{~nm}$, em $460 \mathrm{~nm}$ ) using a BMG Fluostar Optima Fluorescence Plate Reader (BMG Labtech Ltd., Aylesbury, UK). The 
measurement of the Pyocyanin produced by P. aeruginosa PAO1 biofilms was performed using the method described by [87], with slight modifications.

\subsection{Scanning Electron Microscopy (SEM) of Biofilms}

Following exposure of pathogenic biofilms to the marine isolates' supernatants or crude extracts for $24 \mathrm{~h}$ in the CBD, three pegs per treatment, randomly chosen, were removed from the lid of the device and rinsed with $250 \mu \mathrm{L}$ of $0.9 \%$ saline for one minute to remove planktonic and loosely adherent bacteria. The pegs were fixed in separate $1.5 \mathrm{~mL}$ eppendorf tubes containing $1 \mathrm{~mL}$ of $3 \%$ glutaraldehyde in $0.1 \mathrm{M}$ cacodylic acid ( $\mathrm{pH}$ 7.2) overnight, at $4{ }^{\circ} \mathrm{C}$. Following fixation, pegs were washed four times for $30 \mathrm{~min}$ with $250 \mu \mathrm{L}$ of $0.1 \mathrm{M}$ cacodylate buffer at $4{ }^{\circ} \mathrm{C}$. Immediately after the wash, samples were dehydrated at rt in five steps by placing the pegs for $30 \mathrm{~min}$ in $250 \mu \mathrm{L}$ of $50 \%$, $70 \%$ and $90 \%$ and then twice for $30 \mathrm{~min}$ in $100 \%$ ethanol. The pegs were then transferred to a microtitre plate containing $200 \mu \mathrm{L}$ of hexamethyldisilazane (HMDS) and left to dry for $24 \mathrm{~h}$ in a fume cupboard. The specimens were mounted on aluminum stubs, gold sputter coated, and examined using the field emission scanning electron microscope FE-SEM (JEOL JSM-6500F FE-SEM, JEOL Ltd., Tokyo, Japan) or FE-SEM (JEOL JSM-840 SEM, JEOL Ltd., Tokyo, Japan) in which case observations were performed at $15 \mathrm{kV}$ and images captured onto Ilford black and white film.

\subsection{Combinatorial Treatment of PAO1 Biofilms}

To study whether the putative QSI bioactive(s) produced by isolate KS8 could improve the antimicrobial efficacy of tobramycin against planktonic populations of $P$. aeruginosa PAO1, the crude organic extract was tested for its MIC value in combination to tobramycin. To determine the MIC of tobramycin alone, a broth microdilution assay was carried out based on the protocol described in the NCCLS guidelines [84]. In accordance with Christensen et al. [76], the MIC of tobramycin against P. aeruginosa $\mathrm{PAO} 1$ was found to be $0.75 \mathrm{mg} / \mathrm{L}$.

To determine the MIC of tobramycin for PAO1 when used in combination with a sub-MIC $(1 \mathrm{mg} / \mathrm{mL})$ concentration of KS8 crude organic extract, the crude organic extract was re-solubilized in DMSO and a solution $(4 \mathrm{mg} / \mathrm{mL})$ of the extract to be tested was prepared in LB broth (2\% DMSO) and sterilized using a $0.22 \mu \mathrm{m}$ filter. $50 \mu \mathrm{L}$ of the working solution was pipetted in columns 4-12 of a microtitre plate. $50 \mu \mathrm{L}$ of tobramycin in LB broth over the concentration range of $30-0.0003 \mu \mathrm{g} / \mathrm{mL}$ was added to each well of columns 4-12. Finally, $100 \mu \mathrm{L}$ of PAO1 inoculum were added to all wells of columns 4-12. A sterility control ( $200 \mu \mathrm{L}$ of LB broth) was placed in the wells of column one. An untreated control (100 $\mu \mathrm{L}$ of LB broth $+100 \mu \mathrm{L}$ of PAO1 inoculum) was placed in the wells of column two. A solvent control (100 $\mu \mathrm{L}$ of LB broth with $1 \% \mathrm{DMSO}+100 \mu \mathrm{L}$ of PAO1 inoculum) was added to the wells of column three. As a result, the initial working solution ( $4 \mathrm{mg} / \mathrm{mL} 4 \%$ DMSO) of KS8 crude extract and the concentration range of tobramycin will both have been diluted 4 -fold to $1 \mathrm{mg} / \mathrm{mL}$ and 7.5-0.00075 $\mu \mathrm{g} / \mathrm{mL}$ respectively. Plates were placed in an incubator at $37{ }^{\circ} \mathrm{C}$ for $24 \mathrm{~h}$ prior to being read at $590 \mathrm{~nm}$ OD. MIC determination was repeated using doubling dilutions of tobramycin and KS8 extract. 


\subsection{Statistical Analysis}

Statistical analysis was performed using GraphPad Prism ${ }^{\mathrm{TM}} 5.01$ (GraphPad Software Inc., San Diego, CA, USA). In the experiments to screen isolate's supernatants for antibiofilm activity, viable counts of biofilms challenged with each supernatant were compared to untreated biofilms of test organisms, unless otherwise stated. The non-parametric Mann Whitney U-Test was used to compare the effect of each single challenge to the untreated control. The non-parametric Kruskal Wallis test, with a Dunn's Multiple Comparison Test, was used for comparisons between more than two groups and to identify individual differences. All colony count data underwent $\log _{10}$ transformation before statistical analysis to normalize the data. Differences compared to controls were considered significant when $p<0.05(* p<0.05 ; * * p<0.01 ; * * p<0.001)$.

\section{Conclusions}

The Gram-negative opportunistic human pathogen Pseudomonas aeruginosa is a leading causative organism of multi-drug resistant nosocomial infections [88]. In this study, a panel of marine bacteria isolated from the surface of different eukaryotic organisms collected in the rock pools of the intertidal zone of the coast of Ireland and Northern Ireland were screened for QSI and antibiofilm activity against $P$. aeruginosa PAO1. Isolate KS8, identified as a Pseudoalteromonas sp., was found to display strong QSI activity against pigment-based reporter strains C. violaceum ATCC 12472, CV026 and Serratia sp. ATCC 39006 and to cause a significant decrease in biomass and viable counts in $P$. aeruginosa PAO1 biofilms. The crude organic extract of KS8 inhibited the production of pyocyanin and pyoverdin in P. aeruginosa PAO1 further supporting the involvement of QSIs in the antibiofilm effects observed. To conclude, KS8 organic extract and tobramycin were used in a combinatorial approach to determine whether the presence of putative QSIs could enhance the antimicrobial activity of this antibiotic. The MIC of tobramycin used in combination with KS8 extract was $0.075 \mu \mathrm{g} / \mathrm{mL}$, ten times lower than tobramycin alone, further supporting the validity of strategies relying on the use of QSIs to reduce the therapeutic dose of antibiotics.

\section{Acknowledgments}

This research was supported by the Irish Marine Institute under the Beaufort Marine Biodiscovery Research award funded by the Irish Government under the National Development Plan (2007-2013).

\section{Author Contributions}

Alessandro Busetti and Brendan F. Gilmore conceived and designed the experiments; Alessandro Busetti, George Shaw and Julianne Megaw performed the experiments; Alessandro Busetti and Brendan F. Gilmore analyzed the data; Sean P. Gorman and Christine A. Maggs contributed reagents/materials/analysis tools; Alessandro Busetti wrote the paper.

\section{Conflicts of Interest}

The authors declare no conflict of interest. 


\section{References}

1. D’Costa, V.M.; King, C.E.; Kalan, L.; Morar, M.; Sung, W.W.; Schwarz, C.; Froese, D.; Zazula, G.; Calmels, F.; Debruyne, R; et al. Antibiotic resistance is ancient. Nature 2011, 477, 457-461.

2. Pendleton, J.N.; Gorman, S.P.; Gilmore, B.F. Clinical relevance of the ESKAPE pathogens. Expert Rev. Anti-Infect. Ther. 2013, 11, 297-308.

3. Wellington, E.M.; Boxall, A.B.; Cross, P.; Feil, E.J.; Gaze, W.H.; Hawkey, P.M.; Johnson-Rollings, A.S.; Jones, D.L.; Lee, N.M.; Otten, W.; et al. The role of the natural environment in the emergence of antibiotic resistance in Gram-negative bacteria. Lancet Infect. Dis. 2013, 13, 155-165.

4. Fleming, A. On the antibacterial action of cultures of a Penicillium, with special reference to their use in the isolation of B. influenzae. 1929. Bull. World Health Organ. 2001, 79, 780-790.

5. Fromm, S.; Beisswanger, E.; Kasbohrer, A.; Tenhagen, B.A. Risk factors for MRSA in fattening pig herds - A meta-analysis using pooled data. Prev. Vet. Med. 2014, doi:10.1016/ j.prevetmed.2014.08.014.

6. Klevens, R.M.; Edwards, J.R.; Tenover, F.C.; McDonald, L.C.; Horan, T.; Gaynes, R.; National nosocomial infections surveillance system. Changes in the epidemiology of methicillin-resistant Staphylococcus aureus in intensive care units in US hospitals, 1992-2003. Clin. Infect. Dis. 2006, 42, 389-391.

7. Boucher, H.W.; Corey, G.R. Epidemiology of methicillin-resistant Staphylococcus aureus. Clin. Infect. Dis. 2008, 46, S344-S349.

8. Hawkey, P.M. The growing burden of antimicrobial resistance. J. Antimicrob. Chemother. 2008, 62, i1-i9.

9. Boucher, H.W.; Talbot, G.H.; Bradley, J.S.; Edwards, J.E.; Gilbert, D.; Rice, L.B.; Scheld, M.; Spellberg, B.; Bartlett, J. Bad bugs, no drugs: no ESKAPE! An update from the infectious diseases society of America. Clin. Infect. Dis. 2009, 48, 1-12.

10. Talbot, G.H.; Bradley, J.; Edwards, J.E., Jr.; Gilbert, D.; Scheld, M.; Bartlett, J.G. Antimicrobial availability task force of the infectious diseases society of America. Bad bugs need drugs: An update on the development pipeline from the antimicrobial availability task force of the infectious diseases society of America. Clin. Infect. Dis. 2006, 42, 657-668.

11. Fuqua, W.C.; Winans, S.C.; Greenberg, E.P. Quorum sensing in bacteria: The LuxR-LuxI family of cell density-responsive transcriptional regulators. J. Bacteriol. 1994, 176, 269-275.

12. Daniels, R.; Vanderleyden, J.; Michiels, J. Quorum sensing and swarming migration in bacteria. FEMS Microbiol. Rev. 2004, 28, 261-289.

13. Miller, M.B.; Bassler, B.L. Quorum sensing in bacteria. Annu. Rev. Microbiol. 2001, 55, 165-199.

14. Gurich, N.; Gonzalez, J.E. Role of quorum sensing in Sinorhizobium meliloti-alfalfa symbiosis. J. Bacteriol. 2009, 191, 4372-4382.

15. Hentzer, M.; Wu, H.; Andersen, J.B.; Riedel, K.; Rasmussen, T.B.; Bagge, N.; Kumar, N.; Schembri, M.A.; Song, Z.; Kristoffersen, P.; et al. Attenuation of Pseudomonas aeruginosa virulence by quorum sensing inhibitors. EMBO J. 2003, 22, 3803-3815. 
16. Li, Y.H.; Tang, N.; Aspiras, M.B.; Lau, P.C.; Lee, J.H.; Ellen, R.P.; Cvitkovitch, D.G. A quorum-sensing signaling system essential for genetic competence in Streptococcus mutans is involved in biofilm formation. J. Bacteriol. 2002, 184, 2699-2708.

17. Dunstall, G.; Rowe, M.T.; Wisdom, G.B.; Kilpatrick, D. Effect of quorum sensing agents on the growth kinetics of Pseudomonas spp. of raw milk origin. J. Dairy Res. 2005, 72, 276-280.

18. De Kievit, T.R.; Iglewski, B.H. Bacterial quorum sensing in pathogenic relationships. Infect. Immun. 2000, 68, 4839-4849.

19. Li, J.; Chen, J.; Vidal, J.E.; McClane, B.A. The Agr-like quorum-sensing system regulates sporulation and production of enterotoxin and beta2 toxin by Clostridium perfringens Type A non-food-borne human gastrointestinal disease strain F5603. Infect. Immun. 2011, 79, 2451-2459.

20. Fineran, P.C.; Slater, H.; Everson, L.; Hughes, K.; Salmond, G.P. Biosynthesis of tripyrrole and beta-lactam secondary metabolites in Serratia: integration of quorum sensing with multiple new regulatory components in the control of prodigiosin and carbapenem antibiotic production. Mol. Microbiol. 2005, 56, 1495-1517.

21. Hammer, B.K.; Bassler, B.L. Quorum sensing controls biofilm formation in Vibrio cholerae. Mol. Microbiol. 2003, 50, 101-104.

22. Waters, C.M.; Lu, W.; Rabinowitz, J.D.; Bassler, B.L. Quorum sensing controls biofilm formation in Vibrio cholerae through modulation of cyclic di-gmp levels and repression of vpst. J. Bacteriol. 2008, 190, 2527-2536.

23. Darch, S.E.; West, S.A.; Winzer, K.; Diggle, S.P. Density-dependent fitness benefits in quorum-sensing bacterial populations. Proc. Natl. Acad. Sci. USA 2012, 109, 8259-8263.

24. Rasmussen, T.B.; Givskov, M. Quorum-sensing inhibitors as anti-pathogenic drugs. Int. J. Med. Microbiol. 2006, 296, 149-161.

25. Reimmann, C.; Ginet, N.; Michel, L.; Keel, C.; Michaux, P.; Krishnapillai, V.; Zala, M.; Heurlier, K.; Triandafillu, K.; Harms, H.; et al. Genetically programmed autoinducer destruction reduces virulence gene expression and swarming motility in Pseudomonas aeruginosa PAO1. Microbiology 2002, 148, 923-932.

26. Ulrich, R.L. Quorum quenching: enzymatic disruption of $N$-acylhomoserine lactone-mediated bacterial communication in Burkholderia thailandensis. Appl. Environ. Microbiol. 2004, 70, 6173-6180.

27. Wopperer, J.; Cardona, S.T.; Huber, B.; Jacobi, C.A.; Valvano, M.A.; Eberl, L. A quorum-quenching approach to investigate the conservation of quorum-sensing-regulated functions within the Burkholderia cepacia complex. Appl. Environ. Microbiol. 2006, 72, 1579-1587.

28. Lee, S.J.; Park, S.Y.; Lee, J.J.; Yum, D.Y.; Koo, B.T.; Lee, J.K. Genes encoding the $N$-acyl homoserine lactone-degrading enzyme are widespread in many subspecies of Bacillus thuringiensis. Appl. Environ. Microbiol. 2002, 68, 3919-3924.

29. Givskov, M.; de Nys, R.; Manefield, M.; Gram, L.; Maximilien, R.; Eberl, L.; Molin, S.; Steinberg, P.D.; Kjelleberg, S. Eukaryotic interference with homoserine lactone-mediated prokaryotic signalling. J. Bacteriol. 1996, 178, 6618-6622. 
30. Hentzer, M.; Riedel, K.; Rasmussen, T.B.; Heydorn, A.; Andersen, J.B.; Parsek, M.R.; Rice, S.A.; Eberl, L.; Molin, S.; Hoiby, N.; et al. Inhibition of quorum sensing in pseudomonas aeruginosa biofilm bacteria by a halogenated furanone compound. Microbiology 2002, 148, 87-102.

31. Manefield, M.; Rasmussen, T.B.; Henzter, M.; Andersen, J.B.; Steinberg, P.; Kjelleberg, S.; Givskov, M. Halogenated furanones inhibit quorum sensing through accelerated LuxR turnover. Microbiology 2002, 148, 1119-1127.

32. Camara, M.; Williams, P.; Hardman, A. Controlling infection by tuning in and turning down the volume of bacterial small-talk. Lancet Infect. Dis. 2002, 2, 667-676.

33. Brackman, G.; Celen, S.; Hillaert, U.; van Calenbergh, S.; Cos, P.; Maes, L.; Nelis, H.J.; Coenye, T. Structure-activity relationship of cinnamaldehyde analogs as inhibitors of AI-2 based quorum sensing and their effect on virulence of Vibrio spp. PLoS One 2011, 6, e16084.

34. Mellbye, B.; Schuster, M. The sociomicrobiology of antivirulence drug resistance: A proof of concept. MBio 2011, 2, doi:10.1128/mBio.00131-11.

35. Shih, P.C.; Huang, C.T. Effects of quorum-sensing deficiency on Pseudomonas aeruginosa biofilm formation and antibiotic resistance. J. Antimicrob. Chemother. 2002, 49, 309-314.

36. Bjarnsholt, T.; Jensen, P.O.; Rasmussen, T.B.; Christophersen, L.; Calum, H.; Hentzer, M.; Hougen, H.P.; Rygaard, J.; Moser, C.; Eberl, L.; et al. Garlic blocks quorum sensing and promotes rapid clearing of pulmonary Pseudomonas aeruginosa infections. Microbiology 2005, 151, 3873-3880.

37. Brackman, G.; Cos, P.; Maes, L.; Nelis, H.J.; Coenye, T. Quorum sensing inhibitors increase the susceptibility of bacterial biofilms to antibiotics in vitro and in vivo. Antimicrob. Agents Chemother. 2011, 55, 2655-2661.

38. Sperandio, V. Novel approaches to bacterial infection therapy by interfering with bacteria-to-bacteria signaling. Exp. Rev. Anti-Infect. Ther. 2007, 5, 271-276.

39. Defoirdt, T.; Boon, N.; Bossier, P. Can bacteria evolve resistance to quorum sensing disruption? PLoS Pathog. 2010, 6, e1000989.

40. Cornaglia, G.; Mazzariol, A.; Lauretti, L.; Rossolini, G.M.; Fontana, R. Hospital outbreak of carbapenem-resistant Pseudomonas aeruginosa producing VIM-1, a novel transferable metallo-beta-lactamase. Clin. Infect. Dis. 2000, 31, 1119-1125.

41. Singh, V.; Arora, V.; Alam, M.J.; Garey, K.W. Inhibition of biofilm formation by esomeprazole in Pseudomonas aeruginosa and Staphylococcus aureus. Antimicrob. Agents Chemother. 2012, $56,4360-4364$.

42. Kukavica-Ibrulj, I.; Bragonzi, A.; Paroni, M.; Winstanley, C.; Sanschagrin, F.; O’Toole, G.A.; Levesque, R.C. In vivo growth of Pseudomonas aeruginosa strains PAO1 and PA14 and the hypervirulent strain LESB58 in a rat model of chronic lung infection. J. Bacteriol. 2008, 190, 2804-2813.

43. Hoiby, N.; Ciofu, O.; Bjarnsholt, T. Pseudomonas aeruginosa biofilms in cystic fibrosis. Future Microbiol. 2010, 5, 1663-1674.

44. Swift, S.; Downie, J.A.; Whitehead, N.A.; Barnard, A.M.; Salmond, G.P.; Williams, P. Quorum sensing as a population-density-dependent determinant of bacterial physiology. Adv. Microb. Physiol. 2001, 45, 199-270. 
45. Popat, R.; Crusz, S.A.; Diggle, S.P. The social behaviours of bacterial pathogens. Br. Med. Bull. 2008, 87, 63-75.

46. Schuster, M.; Lostroh, C.P.; Ogi, T.; Greenberg, E.P. Identification, timing, and signal specificity of Pseudomonas aeruginosa quorum-controlled genes: A transcriptome analysis. J. Bacteriol. 2003, 185, 2066-2079.

47. Parsek, M.R.; Greenberg, E.P. Sociomicrobiology: the connections between quorum sensing and biofilms. Trends Microbiol. 2005, 13, 27-33.

48. Dang, H.; Lovell, C.R. Bacterial primary colonization and early succession on surfaces in marine waters as determined by amplified rrna gene restriction analysis and sequence analysis of $16 \mathrm{~s}$ rrna genes. Appl. Environ. Microbiol. 2000, 66, 467-475.

49. Dobretsov, S.; Teplitski, M.; Bayer, M.; Gunasekera, S.; Proksch, P.; Paul, V.J. Inhibition of marine biofouling by bacterial quorum sensing inhibitors. Biofouling 2011, 27, 893-905.

50. McClean, K.H.; Winson, M.K.; Fish, L.; Taylor, A.; Chhabra, S.R.; Camara, M.; Daykin, M.; Lamb, J.H.; Swift, S.; Bycroft, B.W.; et al. Quorum sensing and Chromobacterium violaceum: Exploitation of violacein production and inhibition for the detection of $\mathrm{N}$-acylhomoserine lactones. Microbiology 1997, 143, 3703-3711.

51. Suga, H.; Smith, K.M. Molecular mechanisms of bacterial quorum sensing as a new drug target. Curr. Opin. Chem. Biol. 2003, 7, 586-591.

52. Throup, J.P.; Camara, M.; Briggs, G.S.; Winson, M.K.; Chhabra, S.R.; Bycroft, B.W.; Williams, P.; Stewart, G.S. Characterisation of the yenI/yenR Locus from Yersinia enterocolitica mediating the synthesis of two $\mathrm{N}$-acylhomoserine lactone signal molecules. Mol. Microbiol. 1995, 17, 345-356.

53. Fletcher, M.P.; Diggle, S.P.; Camara, M.; Williams, P. Biosensor-based assays for PQS, HHQ and related 2-alkyl-4-quinolone quorum sensing signal molecules. Nat. Protoc. 2007, 2, 1254-1262.

54. Poulter, S.; Carlton, T.M.; Su, X.; Spring, D.R.; Salmond, G.P. Engineering of new prodigiosin-based biosensors of Serratia for facile detection of short-chain $N$-acyl homoserine lactone quorum-sensing molecules. Environ. Microbiol. Rep. 2010, 2, 322-328.

55. Winson, M.K.; Camara, M.; Latifi, A.; Foglino, M.; Chhabra, S.R.; Daykin, M.; Bally, M.; Chapon, V.; Salmond, G.P.; Bycroft, B.W. Multiple $N$-acyl-L-homoserine lactone signal molecules regulate production of virulence determinants and secondary metabolites in Pseudomonas aeruginosa. Proc. Natl. Acad. Sci. USA 1995, 92, 9427-9431.

56. Stintzi, A.; Evans, K.; Meyer, J.M.; Poole, K. Quorum-sensing and siderophore biosynthesis in Pseudomonas aeruginosa: lasR/lasI mutants exhibit reduced pyoverdine biosynthesis. FEMS Microbiol. Lett. 1998, 166, 341-345.

57. Pesci, E.C.; Milbank, J.B.; Pearson, J.P.; McKnight, S.; Kende, A.S.; Greenberg, E.P.; Iglewski, B.H. Quinolone signaling in the cell-to-cell communication system of Pseudomonas aeruginosa. Proc. Natl. Acad. Sci. USA 1999, 96, 11229-11234.

58. Winzer, K.; Falconer, C.; Garber, N.C.; Diggle, S.P.; Camara, M.; Williams, P. The Pseudomonas aeruginosa lectins PA-IL and PA-IIL are controlled by quorum sensing and by RpoS. J. Bacteriol. 2000, 182, 6401-6411. 
59. Kim, H.S.; Park, H.D. Ginger extract inhibits biofilm formation by Pseudomonas aeruginosa PA14. PLoS One 2013, 8, e76106.

60. Flemming, H.C.; Wingender, J. Relevance of microbial extracellular polymeric substances (EPSs)_-Part I: Structural and ecological aspects. Water Sci. Technol. 2001, 43, 1-8.

61. Flemming, H.C.; Wingender, J. Relevance of microbial extracellular polymeric substances (EPSs)_Part II: Technical aspects. Water Sci. Technol. 2001, 43, 9-16.

62. Dheilly, A.; Soum-Soutera, E.; Klein, G.L.; Bazire, A.; Compere, C.; Haras, D.; Dufour, A. Antibiofilm activity of the marine bacterium Pseudoalteromonas sp. strain 3J6. Appl. Environ. Microbiol. 2010, 76, 3452-3461.

63. James, S.G.; Holmstrom, C.; Kjelleberg, S. Purification and characterization of a novel antibacterial protein from the marine bacterium D2. Appl. Environ. Microbiol. 1996, 62, 2783-2788.

64. Bowman, J.P. Bioactive compound synthetic capacity and ecological significance of marine bacterial genus Pseudoalteromonas. Mar. Drugs 2007, 5, 220-241.

65. Bayles, K.W. The biological role of death and lysis in biofilm development. Nat. Rev. Microbiol. 2007, 5, 721-726.

66. Mai-Prochnow, A.; Evans, F.; Dalisay-Saludes, D.; Stelzer, S.; Egan, S.; James, S.; Webb, J.S.; Kjelleberg, S. Biofilm development and cell death in the marine bacterium Pseudoalteromonas tunicata. Appl. Environ. Microbiol. 2004, 70, 3232-3238.

67. Mai-Prochnow, A.; Webb, J.S.; Ferrari, B.C.; Kjelleberg, S. Ecological advantages of autolysis during the development and dispersal of Pseudoalteromonas tunicata biofilms. Appl. Environ. Microbiol. 2006, 72, 5414-5420.

68. Costa-Ramos, C.; Rowley, A.F. Effect of extracellular products of Pseudoalteromonas atlantica on the edible crab Cancer pagurus. Appl. Environ. Microbiol. 2004, 70, 729-735.

69. Holmstrom, C.; Kjelleberg, S. Marine Pseudoalteromonas species are associated with higher organisms and produce biologically active extracellular agents. FEMS Microbiol. Ecol. 1999, 30, 285-293.

70. Teasdale, M.E.; Liu, J.; Wallace, J.; Akhlaghi, F.; Rowley, D.C. Secondary metabolites produced by the marine bacterium Halobacillus salinus that inhibit quorum sensing-controlled phenotypes in gram-negative bacteria. Appl. Environ. Microbiol. 2009, 75, 567-572.

71. Kjer, J.; Debbab, A.; Aly, A.H.; Proksch, P. Methods for isolation of marine-derived endophytic fungi and their bioactive secondary products. Nat. Protoc. 2010, 5, 479-490.

72. Williams, P.; Camara, M.; Hardman, A.; Swift, S.; Milton, D.; Hope, V.J.; Winzer, K.; Middleton, B.; Pritchard, D.I.; Bycroft, B.W. Quorum sensing and the population-dependent control of virulence. Philos. Trans. R. Soc. Lond. B. Biol. Sci. 2000, 355, 667-680.

73. Visca, P.; Imperi, F.; Lamont, I.L. Pyoverdine siderophores: From biogenesis to biosignificance. Trends Microbiol. 2007, 15, 22-30.

74. Lamont, I.L.; Konings, A.F.; Reid, D.W. Iron acquisition by Pseudomonas aeruginosa in the lungs of patients with cystic fibrosis. Biometals 2009, 22, 53-60.

75. Hassan, H.M.; Fridovich, I. Mechanism of the antibiotic action pyocyanine. J. Bacteriol. 1980, $141,156-163$. 
76. Christensen, L.D.; van Gennip, M.; Jakobsen, T.H.; Alhede, M.; Hougen, H.P.; Hoiby, N.; Bjarnsholt, T.; Givskov, M. Synergistic antibacterial efficacy of early combination treatment with tobramycin and quorum-sensing inhibitors against Pseudomonas aeruginosa in an intraperitoneal foreign-body infection mouse model. J. Antimicrob. Chemother. 2012, 67, 1198-1206.

77. Anderson, C.M.; Haygood, M.G. Alpha-proteobacterial symbionts of marine bryozoans in the genus Watersipora. Appl. Environ. Microbiol. 2007, 73, 303-311.

78. Bauer, A.W.; Kirby, W.M.; Sherris, J.C.; Turck, M. Antibiotic susceptibility testing by a standardized single disk method. Am. J. Clin. Pathol. 1966, 45, 493-496.

79. Assefa, E.; Beyene, F.; Santhanam, A. Effect of temperature and ph on the antimicrobial activity of inhibitory substances produced by lactic acid bacteria isolated from Ergo, an Ethiopian traditional fermented milk. Afr. J. Microbiol. Res. 2008, 2, 229-234.

80. Mushtaq, S.; Warner, M.; Cloke, J.; Afzal-Shah, M.; Livermore, D.M. Performance of the Oxoid M.I.C.Evaluator Strips compared with the Etest assay and BSAC agar dilution. J. Antimicrob. Chemother. 2010, 65, 1702-1711.

81. McLean, R.J.; Pierson, L.S., 3rd; Fuqua, C. A simple screening protocol for the identification of quorum signal antagonists. J. Microbiol. Methods 2004, 58, 351-360.

82. Stepanovic, S.; Vukovic, D.; Dakic, I.; Savic, B.; Svabic-Vlahovic, M. A modified microtiter-plate test for quantification of staphylococcal biofilm formation. J. Microbiol. Methods 2000, 40, 175-179.

83. Miles, A.A.; Misra, S.S.; Irwin, J.O. The estimation of the bactericidal power of the blood. J. Hyg. Lond. 1938, 38, 732-749.

84. NCCLS. Methods for Dilution Antimicrobial Susceptibility Tests for Bacteria That Grow Aerobically M7-A5, 5th ed.; National Committee for Clinical Laboratory Standards: Wayne, PA, USA, 2000.

85. Ceri, H.; Olson, M.E.; Stremick, C.; Read, R.R.; Morck, D.; Buret, A. The Calgary biofilm device: New technology for rapid determination of antibiotic susceptibilities of bacterial biofilms. J. Clin. Microbiol. 1999, 37, 1771-1776.

86. Romanowski, K.; Zaborin, A.; Fernandez, H.; Poroyko, V.; Valuckaite, V.; Gerdes, S.; Liu, D.C.; Zaborina, O.Y.; Alverdy, J.C. Prevention of siderophore-mediated gut-derived sepsis due to $P$. aeruginosa can be achieved without iron provision by maintaining local phosphate abundance: Role of pH. BMC Microbiol. 2011, 11, doi:10.1186/1471-2180-11-212.

87. Fothergill, J.L.; Panagea, S.; Hart, C.A.; Walshaw, M.J.; Pitt, T.L.; Winstanley, C. Widespread pyocyanin over-production among isolates of a cystic fibrosis epidemic strain. BMC Microbiol. 2007, 7, 45 .

88. Aloush, V.; Navon-Venezia, S.; Seigman-Igra, Y.; Cabili, S.; Carmeli, Y. Multidrug-resistant Pseudomonas aeruginosa: risk factors and clinical impact. Antimicrob. Agents Chemother. 2006, $50,43-48$.

(C) 2014 by the authors; licensee MDPI, Basel, Switzerland. This article is an open access article distributed under the terms and conditions of the Creative Commons Attribution license (http://creativecommons.org/licenses/by/4.0/). 